University of Rhode Island

DigitalCommons@URI

Ocean Engineering Faculty Publications

Ocean Engineering

1983

\title{
Constraints Upon Water Advection in Sediments of the Mariana Trough
}

Dallas H. Abbott

William Menke

Roger Morin

University of Rhode Island

Follow this and additional works at: https://digitalcommons.uri.edu/oce_facpubs

Terms of Use

All rights reserved under copyright.

\section{Citation/Publisher Attribution}

Abbott, D. H., W. Menke, and R. Morin (1983), Constraints upon water advection in sediments of the Mariana Trough, J. Geophys. Res., 88(B2), 1075-1093, doi: 10.1029/JB088iB02p01075. Available at: https://doi.org/10.1029/JB088iB02p01075

This Article is brought to you for free and open access by the Ocean Engineering at DigitalCommons@URI. It has been accepted for inclusion in Ocean Engineering Faculty Publications by an authorized administrator of DigitalCommons@URI.For more information, please contact digitalcommons-group@uri.edu. 


\title{
CONSTRAINTS UPON WATER ADVECTION IN SEDIMENTS OF THE MARIANA TROUGH
}

\author{
Dallas H. Abbott and William Menke
}

Lamont-Doherty Geological Observatory and Department of Geological Sciences of Columbia Untversity Palisades, New York 10964

Roger Morin

Department of Ocean Engineering, University of Rhode Island Narragansett, Rhode Island 02881

Abstract. Thermal gradient measurements, consolidation tests, and pore water compositions from the Mariana Trough imply that water is moving through the sediments in areas with less than about 100 m of sediment cover. The maximum advection rates implied by the thermal measurements and consolidation tests may be as high as $10^{-5} \mathrm{~cm} \mathrm{~s} \mathrm{~s}^{-1}$ but are most commonly in the range of 1 to $5 \times 10^{-6} \mathrm{~cm} \mathrm{~s}^{-1}$. Theoretical calculations of the effect of the highest advection rates upon carbonate dissolution indicate that dissolution may be impeded or enhanced (depending upon the direction of flow) by a factor of 2 to 5 times the rate for diffusion alone. The average percentage of carbonate is consistently higher in two cores from the area with no advection or upward advection than the average percentage of carbonate in three cores from the area with downward advection. This increase in average amount of carbonate in cores with upward moving water or no movement cannot be attributed solely to differences in water depth or in amount of terrigenous dilution. If the sediment column acts as a passive boundary layer, then the water velocities necessary to affect chemical gradients of silica are in the range $10^{-9}$ to $10^{-10} \mathrm{~cm} \mathrm{~s} \mathrm{~s}^{-1}$. However, if dissolution of silica occurs within the sediment column, then the advection velocities needed to affect chemical gradients are at least $3 \times 10^{-8} \mathrm{~cm} \mathrm{~s}^{-1}$ and may be as high as $3 \times 10^{-6} \mathrm{~cm} \mathrm{~s}^{-1}$. This order of magnitude increase in advection velocities when chemical reactions occur within the sediments is probably applicable to other cations in addition to silica. If so, then the advection velocities needed to affect heat flow $\left(>10^{-8} \mathrm{~cm} \mathrm{~s}^{-1}\right)$ and pore water chemical gradients are much nearer in magnitude than previously assumed.

\section{Introduction}

On a recent cruise to the Mariana Trough, the back arc spreading center west of the Marianas arc (Figure 1), a heat flow survey accompanied by coring was made in the vicinity of Deep Sea Drilling Project (DSDP) sites 453, 454, 456 and the spreading center. The heat flow, pore water compositions, physical property, and carbonate content data from cores from this cruise and the DSDP sites provide information on the extent and effects of water circulation within the sediment column. We first discuss the probable effects of water circu-

Copyright 1983 by the American Geophysical Union. lation upon pore water composition, heat flow, and physical properties. Our gravity, core and heat flow data are then used to estimate the effects and extent of hydrothermal activity in the Marianas sediment.

\section{Thermal Effects of Hydrothermal Circulation}

Hydrothermal circulation of water within the upper few kilometers of oceanic crust is now a reasonably well-documented phenomenon [Anderson et al., 1979; Lister, 1972; Bodvarsson and Lowell, 1972; Sclater and K1itgord, 1973; Davis and Lister, 1974]. This circulation of cool ocean water within the basalt results in low heat flow measurements compared to theoretical values for young oceanic crust [Anderson and Hobart, 1976]. The reasons for the low heat flow are three fold.

1. The convective circulation of seawater cools the upper 3-6 km of basalt faster than heat can be replaced from below by conduction. As a result, the upper layers of basalt are cooler than theoretical, purely conductive models would predict.

2. Most heat flow measurements are made in sediment ponds that lie above the coldest crust. In porous media with topographically driven water circulation, the areas of upwelling hot water are concentrated upon topographic highs [Hartline and Lister, 1981]. As a consequence, the temperature at the sediment-basement Interface is lower in the valleys. In most young areas of oceanic crust, only the valleys have sediment cover sufficiently thick for coring and thermal measurements.

3. Convective downward movement of water within the sediment results in additional lowering of the heat flow by concentrating the maximum thermal gradient at the bottom of the sediment column, at the sediment-basement interface (F1gure 2). Core and multiple penetration heat flow measurements determine the thermal gradient in the upper 5-12 m of the sediment, missing the region with the maximum thermal gradient, 1.e., the sediment-basement interface, in downwelling areas with thick sediment cover.

By themselves, the low and Iinear thermal profiles can be interpreted as the result of convection within both the sediment and the basalt or as the product of convection in the basalt alone. Evidence exists for water clrculation within the sediments in regions of thin sediment cover [Anderson et al., 1979; Becker and Von Herzen, 1981]. We use supplementary geochemical and physical property data to constrain better the cause of low thermal gradients in the Marlanas, where most sediment thicknesses are greater than $30 \mathrm{~m}$. 


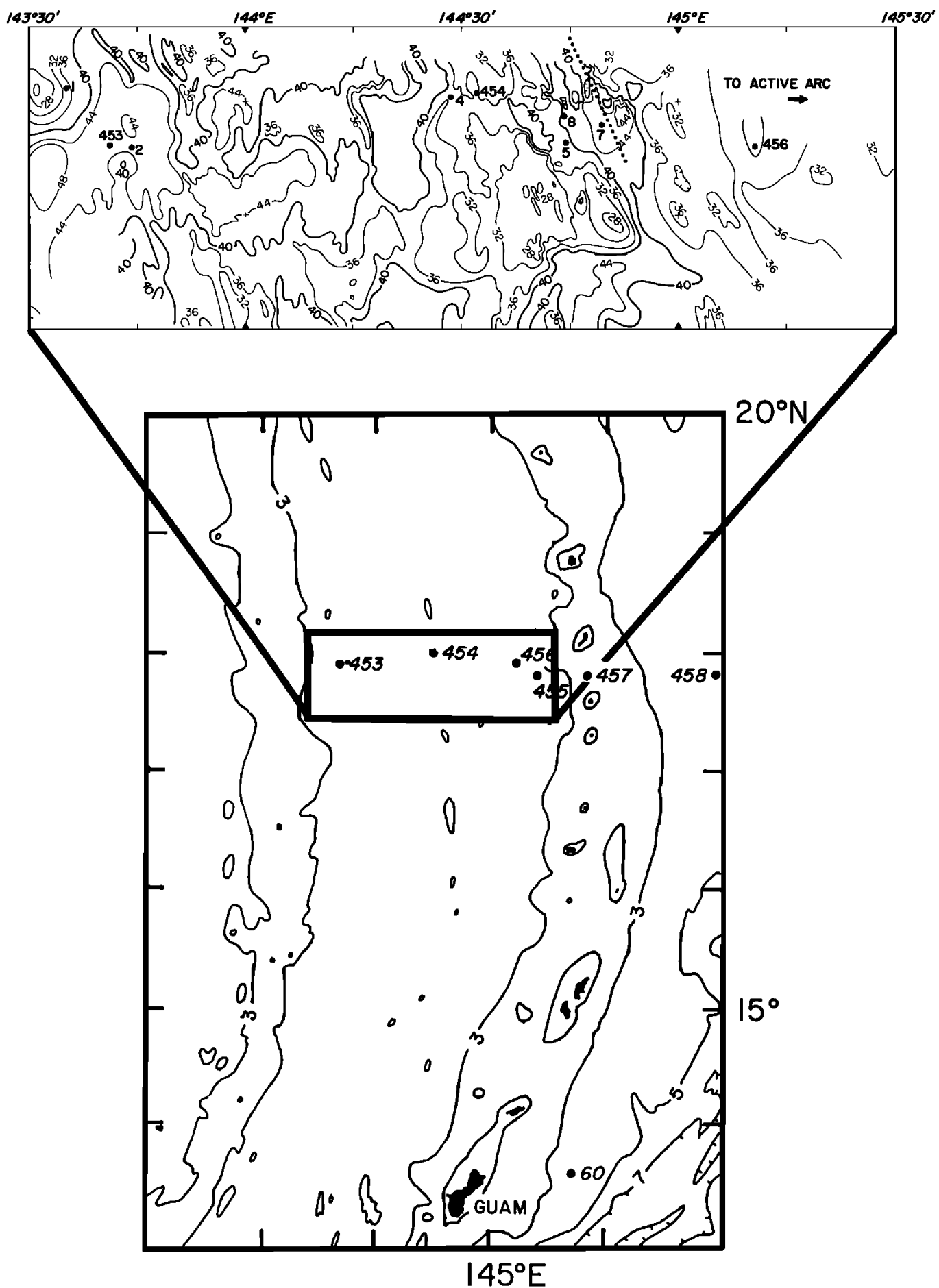

Fig. 1. Location map of DSDP sites and gravity cores. The latitude range of the area shown in detail is $17^{\circ} 30^{\prime}$ to $18^{\circ} 15^{\prime}$. The contour interval is $400 \mathrm{~m}$. Contours are courtesy of D. Hussong with some additions by C. Mrozowski and B. Taylor. The dotted line right of center on the blowup marks approximate locations of the spreading center (Marlana Trough).

\section{Chemical Effects}

Hydrothermal circulation of seawater within the basalt results in alteration of the basalt, with consequent changes in basaltic pore water composition. A microprobe study of the composition of altered and unaltered basalt glass in a low-tem- perature zone [Ailin-Pyzik and Sommers, 1981] indicated that the average basalt loses $717 \mathrm{~g}$ silica, $165 \mathrm{~g}$ magnestum, and $309 \mathrm{~g}$ of calcium (all oxides) per $1000 \mathrm{~cm}^{3}$ of original glass. Some of this material is reprecipitated within the basalt as zeolites, clay minerals, or calcite, so that the composition of the resulting fluid is not necessarily 
enriched (relative to seawater) in silica, $\mathrm{Mg}$, or $\mathrm{Ca}$. The consensus of the work of Allin-Pyzik and Sommer [1981] and the five papers they cite is that the resulting pore fluid has more silica and calcium than seawater and a slight depletion in magnesium.

Rapidly upwelling hydrothermal waters should have compositions closest to basaltic pore water, whereas downwelling water should have a composition closer to that of seawater. Diagenetic processes within the sediment will control the pore water composition if a given cation is added to the pore water more rapidly than the ion is removed by advection or diffusion. Dissolution of siliceous tests of organisms can produce increases in the pore water silica. Calcium can be added to the pore water by diagenetic reactions with organic matter [Sayles, 1981] or with volcanic material. Siliceous tests and volcanic material average about 4 and $80 \%$, respectively (1n the Marianas sediments we examined). Enrichments of calcium and silica in the sedimentary pore water of the Marianas may thus result either from reactions in the sediment or in the basalt.

Hydrothermally (basalt-based) and diagenetically (sediment-based) induced changes in pore water composition can be distinguished upon two grounds.

1. The shape of the chemical composition versus the depth profile will differ depending upon the location of the dominant source of reactant. For instance, in an area with downward advecting water dominated by basalt reactions, the concentration of an element will remain at seawater composition until quite close to the sedimentbasement interface. Near this interface the concentration will rapidly change to that of the pore water in the basalt. However, if the sediment is the dominant region of reactions, the concentration will change at shallow depths in the sediment.

2. The magnitude of the compositional differences from seawater is generally greatest for diagenetic reactions. The maximum calcium and magnesium anomalies observed in hydrothermally dominated pore waters near the mounds in the Galapagos [Maris et al., 1979] were +2 and $-1 \mathrm{mM} \mathrm{1} 1^{-1}$, respectively. In contrast, diagenetically induced anomalies may be 20 times as large.

The sign of the change in pore water composition caused by diagenests in the sediment column and reactions in the basement appears to be the same. $\mathrm{Ca}, \mathrm{LI}, \mathrm{Mn}$, and silica increase, and $\mathrm{Mg}$ decreases from seawater values. Only the magnitude of the change in pore water composition and the distribution of these changes within the sediment column provide information on the major sources of changes in pore water chemistry. The fact that the sign of chemical anomaly (for many important elements) is the same is not particularly surprising. At least $80 \%$ of the Marlanas sediment is volcanic in origin, and most of this is glass. The basement and sediment in the Marianas are very similar in chemical composition.

\section{Physical Property Effects}

Hydrothermal circulation also changes the physical properties of the basalt and overlying sediment. Hydrothermal removal of silica, $\mathrm{Mg}, \mathrm{Ca}$, and many other elements from unaltered basalt is balanced in part by precipitation of calcite, zeolites, and clay minerals in fractures and voids [Ailin-Pyzik
TEMPERATURE or COMPOSITION

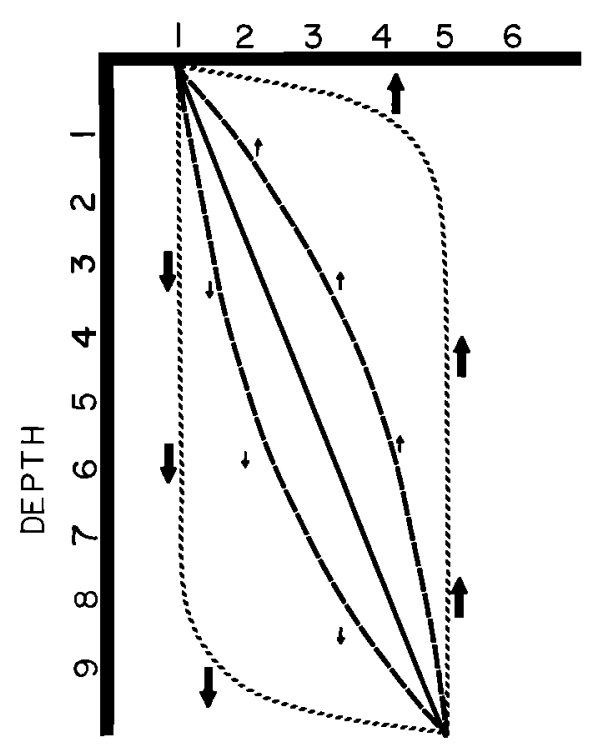

Fig. 2. Chemical or thermal profiles in the sediment column. Seawater has a lower temperature or chemical concentration than the basalt. No heat sources or chemical sources are assumed to exist within the sediment column. The linear profile exists when diffusion controls the chemistry or thermal structure of the sediment. Upward movement of water fast enough to overcome diffusion causes profiles like those next to the upward pointing arrows. Rapid downward movement of water will result in profiles like those next to the downward pointing arrows. The curvature of the profiles is a result of the ratio of the diffusion rate to the advection rate. Since the thermal diffusivity is much higher than the chemical diffusivity, chemical profiles will be more distorted than thermal profiles for the same advection rates.

and Sommers, 1981]. All of these alteration products are less dense than the original basaltic rock, so that some loss of material to the water column must occur to preserve volume. These lowdensity alteration products may slow further hydrothermal alteration by producing protective 'rinds' and by reducing the permeability of the rock [Anderson and Zoback, 1982]. The relative speed of alteration within the sediment and the basalt is an important parameter, which we consider in more detail later.

Hydrothermal effects upon the physical properties of the sediment can be divided into two groups: effective stress and chemical alteration.

The effective stress is the buoyant weight of the overburden minus the excess pore pressure. If the excess pore pressure is zero, the pore pressure is hydrostatic. Hydrothermal water circulation in the basalt generates excess pore pressures, which in turn can cause nonhydrostatic pressures within the sediment column. Downward water movement in the sediment is caused by negative (below hydrostatic) excess pore pressures which increase effective stress and thus increase the rate of consolidation of the sediment. Large excess pore pressures occur when water is forced rapidly through rock of low hydraulic conductivity. Upward 
water movement occurs in the presence of positive excess pore pressures, which decrease the effective stress and rate of consolidation of the sediment. From effective stress effects alone, one would expect the depth gradients of shear strength, permeability, porosity, and seismic velocity to be greatest in sediments with downwelling water and least in those with upwelling water.

An additional result of water circulation within the sediments may be the promotion of sediment slides and/or increased eroston in regions of upwelling water [Abbott et al., 1981]. The higher water contents in upwelling regions caused by decreased effective stress and consolidation rates would result in sediments with higher porosity. Shear strength is lower in sediments with h1gh porosity and high water contents, since the water craction has no shear strength [Lambe and Whitman, 1979]. The vulnerability of sediment to erosive currents and to slope fallure is increased with lowered shear strength [Kelly et a1., 1980], so that thinner sediment cover may result in regions of upwelling water.

Chemical alteration of the sediments by hydrothermal fluids may also change the physical properties of the sediment. The sediment we sampled in the Marlanas averaged $27 \%$ particles larger than 38 . Ninety percent of this coarse material is volcanic glass. The fine fraction is difficult to Identify optically but appears to be volcanic glass as well. We estimate that $70 \%$ or more of the whole sediment consists of arc-derived volcanoclastic material. About $43 \%$ of the original weight of basaltic glass may be lost through alteration [Ailin-Pyzin and Sommer, 1981]. This weight loss may not result in an equivalent volume loss. Nevertheless, there is a possibility that $28 \%$ or more of the sediment volume is lost due to diagenetic alteration of the volcanic glass. Any alteration and consequent volume loss would be most pronounced in active hydrothermal areas (either upwelling or downwelling) because the faster cycle time of the pore water would result in pore water compositions further from equilibrium with the sediment particles. The higher reaction rates resulting from nonequilibrium pore water compositions would be especially pronounced in areas of upwelling, where the most rapld advection results in high thermal gradients (and warmer pore water) close to the sediment-water interface. In downwelling regions the pore waters are the furthest from equilibrium with basalt. However, this disequilibrium may be balanced by the colder temperatures (and consequently slower reaction rates).

Reactions with seawater and hydrothermal solutions could also result in increased dissolution of the blogenic silica and carbonate in the Marianas sediment, which compose about 4 and $1-2 \%$ respectively of the total material. Seawater is unsaturated in both carbonate and silica throughout the study area, so increased dissolution of both these materials could make a contribution to losses of material in hydrothermal areas. Any increase in dissolution would result in more rapid compaction of the sediment for two reasons.

1. Dissolution occurs most rapidly at the points of greatest stress. Therefore, material at grain to grain contacts would dissolve first.

2. Fine-grained material dissolves more rapidly than coarser particles due to the greater surface to volume ratio of the smaller particles. The porosity of the sediments is highly dependent upon the grain size distribution. The highest porosity sediments are those with the most fine particles. A decrease in the amount of fine particulate matter would therefore result in lower porosities and more mass concentrated within the same volume.

The combination of increased dissolution in upwelling and downwelling regions and accelerated erosion and slope failure in upwelling regions should combine to produce notable decreases in apparent sedimentation rate wherever hydrothermal processes are present in the sediment column. The apparent sedimentation rate has been observed to increase with age in the Indian Ocean as hydrothermal activity decreased [Abbott et a1., 1981]. A similar correlation has not been observed in the Marianas, probably because of poor stratigraphic control and locally varlable sedimentation rates.

\section{Gravity Core Data}

Our six cores from the Marianas back arc basin were taken from oceanic crust 0 to $6 \mathrm{~m} . \mathrm{y}$. old covered with between 0.5 and $100 \mathrm{~m}$ of sediment (Table 1). The cores were taken sequentially in a traverse starting upon the oldest crust and moving progressively toward younger crust (Figure 1 ). Cores 1 and 2 are located near DSDP site 453 and core 4 near site 454 . Cores 5,7 , and 8 are from the trough (spreading center). Cores 3 and 6 were not recovered. All cores can be considered gravity cores, since early triggering of the piston resulted in the recovery of the topmost layers in every location.

All but core 2 have accompanying pore water analyses. We rely primarily upon the pore water compositions (determined by J. Gleskes, personal communication, 1979) to infer the existence and direction of sedimentary pore water circulation. The pore water data are subject to squeezing artifacts. Calcium is reduced by $1-3 \%$, magnesium by $3-5 \%$, and silica is increased by about $50 \%$ [Schink et al., 1974]. Calctum shows significant differences from core to core and has the smallest squeezing artifacts, so we rely most upon calcium data in making our interpretations. Although magnesium also has small squeezing artifacts, its variation within a core is as great as the differences between cores. Magnesium might be useful with more samples per core but is not interpretable in our data set. Silica has large squeezing artifacts but shows significant differences from core to core, so we give it secondary weight in our interpretations. Lithium and manganese have small squeezing artificts (1-3\%); however, they also show large variations within a core. Manganese in particular may be released into the pore water during squeezing of zones with higher concentrations of organic matter. Manganese is very sensitive to the oxidation state of the pore fluid and has a rapid reaction rate [Elderfield et a1., 1981].

\section{Cores Near DSDP Site 453}

Piston core 1 is the only core near site 453 for which pore water data are available. This core had both the largest deviations from seawater composition of any core and the only linear increase of calcium with increasing depth subbottom 
TABLE 1. Sedimentologic Data for Cores and DSDP Sites

\begin{tabular}{rccccc}
\hline Core & $\begin{array}{c}\text { Water Depth, } \\
\mathrm{m}\end{array}$ & $\begin{array}{c}\text { Sediment, } \\
\text { Thickness }\end{array}$ & $\begin{array}{c}\text { Age, } \\
\text { m.y. }\end{array}$ & $\begin{array}{c}\text { Sedimentation } \\
\text { Rate; } \\
\text { m/m.y. }\end{array}$ & $\begin{array}{c}\text { Carbonate, } \\
\%\end{array}$ \\
\hline & & & & 18 & 3.5 \\
2 & 3785 & 100 & 5.9 & 0.68 & 0.1 \\
4 & 4679 & 3.9 & 5.7 & 5.8 & 2.3 \\
5 & 4142 & 9.2 & 1.6 & 50 & 0.1 \\
7 & 3876 & 3.3 & 0.55 & 51 & 0.1 \\
8 & 4803 & 5.2 & 0.10 & 52 & 50 \\
454 & 4227 & 24 & 0.47 & 1.3 & \\
\hline 53 & 3816 & 67 & 5.7 & & \\
\hline
\end{tabular}

(Figure 3a, Table 2). Manganese and 1ithium appear to parallel this trend. Silica is consistently higher than any other core. Core 1 is also from the oldest crust $(5.8 \mathrm{~m} . \mathrm{y}$.$) with the thickest sedi-$ ment $(100 \mathrm{~m})$. Linear changes of pore water composition with depth, coupled with large deviations from seawater composition are characteristic of sediment with no water movement. Although the chemical gradients might also be associated with very slow upward water movements, the advection rate is probably significant only for chemical and not thermal measurements.

Two heat flow stations nearest to core 1 , both 900 m distant with linear temperature profiles, yield conductive heat flow of 125 and $97 \mathrm{mWn}^{-2}$ (Figure 4). The linear thermal profiles indicate that no upwelling of water more rapid than about $5 \times 10^{-7} \mathrm{~cm} \mathrm{~s}^{-1}$ is occurring in the vicinity of core 1. The fact that all three thermal measurements in the vicinity of core 1 are within $30 \%$ of the neighboring heat flow values is also suggestive of no or very slow sedimentary pore water advection. (The theoretical heat flow for $5.8-\mathrm{m}$.y.crust is $208 \mathrm{~mW} \mathrm{~m}^{-2}$ [Parsons and Sclater, 1977; Lister, 1975], almost twice the observed value.) Site 453, which is covered with $450 \mathrm{~m}$ of sediment, is located just below the hill upon which core 1 was taken. Diagenetic reactions within the sediment column cause the Ca values in the upper part of the section at site 453 to increase uniformly at the rate of $0.13 \mathrm{mM} 1^{-1} \mathrm{~m}^{-1}$ [Gieskes and Johnson, 1982]. The rate of calcium increase with depth in core 1 is $0.67 \mathrm{mM} 1^{-1} \mathrm{~m}^{-1}$, about 5 times higher. from this evidence alone, one might attribute this difference in gradient solely to the difference in sediment thickness between the two sites, which is also a factor of 5 . However, in the lower part of hole 453, the concentrations of $\mathrm{Ca}$ and $\mathrm{Mg}$ begin to decrease. Near the sediment-basement contact, the concentrations of $\mathrm{Ca}$ and $\mathrm{Mg}$ again approach seawater values. These observations strongly suggest that the calcium anomalies are a result of reactions occurring within the sediment.

The heat flow at site 453 is $102 \mathrm{~mW} \mathrm{~m}^{-2}$ [Uyeda and Horai, 1982], also about half the theoretical value. These low heat flow values indicate that some convective heat exchange is still occurring in this area, although not necessarily in the Immediate vicinity of site 453 or the cores.

Core 2 was taken from a hill immediately to the west of site 453. Heat flow measurements on this hill were highly variable, with many other nonlinear profiles [Anderson et al., 1982]. Core 2 has no pore water data but is of interest because of its location and because it is the most visibly a1tered of all the cores. Core 2 has a high clay content, shown by its high porosity and low sandsized fraction. It also has the slowest sedimentation rate. These observations support the idea that large amounts of alteration and low sedimentation rates are connected. The nearest heat flow observations along the strike of the topography (28 and $34 \mathrm{~mW} \mathrm{~m}^{-2}$, figure 4) are both nonlinear, suggesting that the high-alteration and low-sedimentation rate at this core are connected with sedimentary pore water circulation.

\section{Advection in the Vicinity of DSDP Site 454}

Core 4 is located just west of site 454 , on the side of a hill. Site 454, with a sediment thickness of $67 \mathrm{~m}$, had no pore water gradients [Gieskes and Johnson, 1982]. The theoretical heat flow for $1.3-\mathrm{m} . \mathrm{y} .-\mathrm{old}$ crust is $440 \mathrm{~mW} \mathrm{~m} \mathrm{~m}^{-2}$, much higher than the observed heat flow. The low heat flow and lack of chemlcal gradients suggest downward pore water advection is occurring in the sediment pond containing site 454 . Core 4 has pore water calcium values that are significantly above seawater composition, when corrected for squeezing artifacts (Table 2). Calcium values are consistently higher than seawater values throughout the core rather than varying with depth. We interpret these high calcium values as due to upward advection of hydrothermal waters. The average silica values for core 4 are not as high as in core 1 but average significantly above the average silica in cores 5,7 , and 8 . Cores 5, 7, and 8 all have pore water Ca of seawater composition, so even with squeezing artifacts, relative enrichment of both calcium and silica occurs in the pore water of core 4 . Both silica and calcium in core 4 are high and relatively constant with depth (Figure $3 \mathrm{~b}$ ), a result consistent with upward water advection of hydrothermal water. Support for this interpretation is gained from the two nearest thermal measurements, less than $400 \mathrm{~m}$ away (Figure 5). The heat flow values are 61 and $101 \mathrm{~mW} \mathrm{~m}^{-2}$, measured from nonlinear temperature profiles that indicate water upwelling at velocities of $2 \times 10^{-6}$ and $3 \times 10-6 \mathrm{~cm} \mathrm{~s}^{-1}$ [Anderson et al., 1982].

\section{Downward Advection Near the Trough}

Piston cores 5, 7, and 8 are all close to the spreading center (Figure 1 ). The pore water cal- 

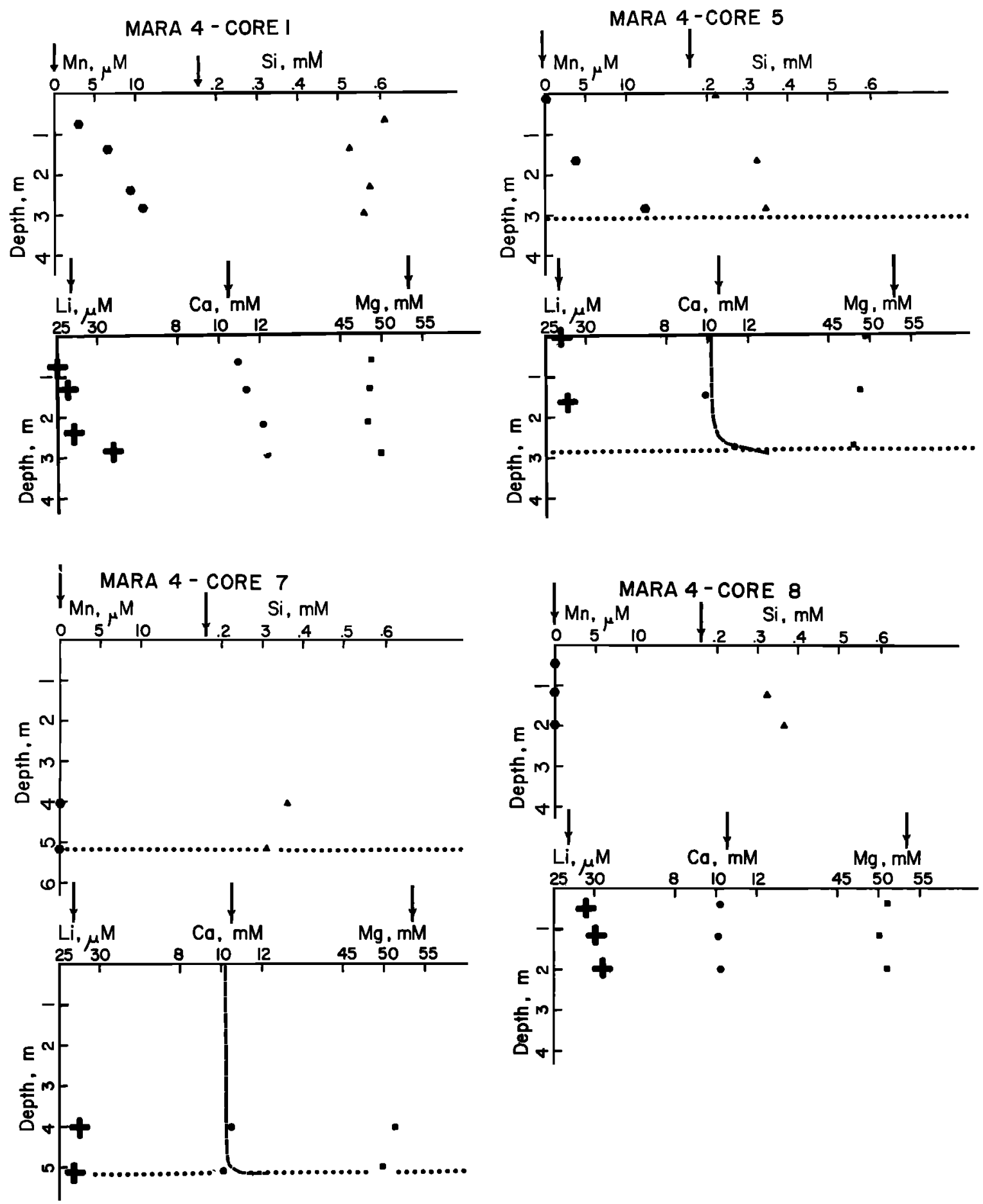

Fig. 3a. Composition of pore water in $\mu \mathrm{M}^{-1}$ with increasing depth subbottom. Dotted lines at the base of piston core 7 and piston core 5 represent the sediment-basement interface. Arrows give composition of seawater for each element.

cium for all three cores is indistinguishable from that of seawater (Table 2). The silica values are higher than seawater, even when squeezing artifacts are taken into account. However, the average silica values for all three cores are within the standard deviations for individual cores and are consistently lower than for cores 1 and 4. Seawater values of pore water $\mathrm{Ca}$ are sometimes interpreted as the result of low organic matter contents within the sediment rather than as a result of advection. Most of the organic matter in deep-sea sediments comes from the calcareous and siliceous test of marine organisms. Siliceous tests make up approximately $4 \%$ of the surface sediments, and carbonate tests average about $2 \%$ of the sediments. In most areas of the ocean, carbonate is the major biogenic component of the sediment and thus the major source of or- 
ganic carbon. The fact that the organic carbon content of deep-sea cores is related to carbonate preservation is shown by the tracking of the fractions of organic carbon and carbonate in the cores described by Heath et al. [1977]. When the sediment is deposited in deep water undersaturated in carbonate ion, much of the organic carbon is removed in the water column or at the sediment-water interface. Little organic matter is left to be incorporated into the sediment. Nevertheless, the calcium anomaly at site 453 indicates that some organic matter. remains even at the rather deep depth of $4693 \mathrm{~m}$. As long as water advection is not present, any core in shallower water should also have pore water anomalies due to organic matter degradation. The seawater calcium values in the shallower water cores 5 and 8 are therefore evidence for water advection. Core 7 is not substantially deeper than site 453 , so that 1 ts calcium value (also seawater composition) is also likely due to water advection. The direction of advection is most likely downward, although seawater calcium values are sometimes reported in upwelling locations (M. Bender, personal communfcation, 1980).

\section{Physical Property Measurements}

Consolidation tests were performed to determine the maximum depth of burial of samples from the cores. This test estimates the maximum past overburden pressure by loading the sample in the lab-
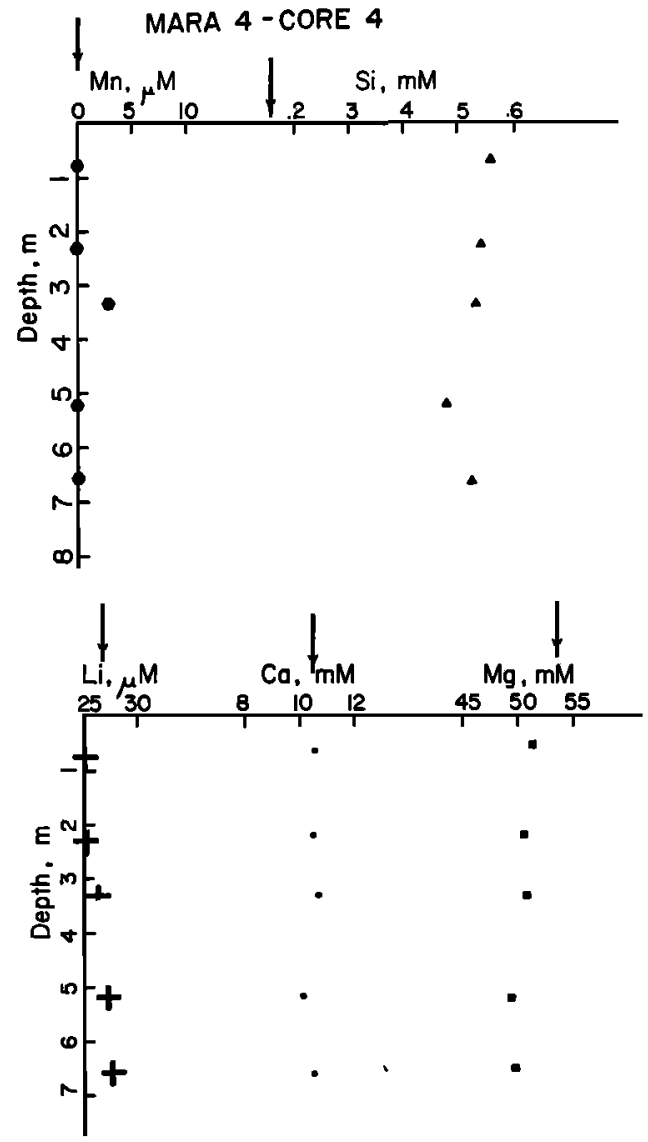

Fig. 3b. Composition of pore water with increasing depth subbottom for core 4. Arrows give the composition of seawater for each element.
TABLE 2. Physical Property Data for Cores

\begin{tabular}{|c|c|c|c|c|}
\hline Core & $\begin{array}{c}\text { Depth, } \\
\text { cm }\end{array}$ & $\begin{array}{l}\text { Permeab } 11 i t y, \\
\mathrm{~cm} \mathrm{~s}\end{array}$ & $\underset{\%}{\text { Porosity, }}$ & $\begin{array}{l}\text { Weight \% } \\
>38 \mu\end{array}$ \\
\hline 1 & $\begin{array}{r}13 \\
105 \\
207 \\
308\end{array}$ & $\begin{array}{l}3 \times 10^{-5} \\
2 \times 10^{-5} \\
1 \times 10^{-5} \\
1 \times 10^{-5}\end{array}$ & $\begin{array}{l}82 \\
77 \\
75 \\
54\end{array}$ & $\begin{array}{l}38 \\
34 \\
29\end{array}$ \\
\hline 2 & $\begin{array}{r}70 \\
173 \\
285 \\
376\end{array}$ & $\begin{array}{l}3 \times 10^{-5} \\
2 \times 10^{-5} \\
1 \times 10^{-5} \\
4 \times 10^{-5}\end{array}$ & $\begin{array}{l}83 \\
83 \\
71 \\
85\end{array}$ & $\begin{array}{r}15 \\
18 \\
4\end{array}$ \\
\hline 4 & $\begin{array}{r}57 \\
183 \\
230 \\
331 \\
430 \\
506 \\
590 \\
732 \\
822\end{array}$ & $\begin{array}{l}3 \times 10^{-5} \\
2 \times 10^{-6} \\
2 \times 10^{-5} \\
1 \times 10^{-5} \\
2 \times 10^{-5} \\
2 \times 10^{-5} \\
1 \times 10^{-5} \\
9 \times 10^{-6} \\
1 \times 10^{-5}\end{array}$ & $\begin{array}{l}74 \\
75 \\
79 \\
74 \\
74 \\
79 \\
80 \\
72 \\
76\end{array}$ & $\begin{array}{l}54 \\
29 \\
34 \\
31 \\
36 \\
29 \\
23 \\
36 \\
34\end{array}$ \\
\hline 5 & $\begin{array}{r}69 \\
105 \\
219\end{array}$ & $\begin{array}{l}5 \times 10^{-5} \\
1 \times 10^{-5} \\
9 \times 10^{-6}\end{array}$ & $\begin{array}{l}74 \\
72 \\
70\end{array}$ & \\
\hline 7 & $\begin{array}{l}312 \\
413\end{array}$ & $\begin{array}{l}5 \times 10^{-5} \\
2 \times 10^{-5}\end{array}$ & $\begin{array}{l}76 \\
75\end{array}$ & $\begin{array}{l}34 \\
34\end{array}$ \\
\hline 8 & $\begin{array}{r}46 \\
115 \\
196\end{array}$ & $\begin{array}{l}7 \times 10^{-5} \\
2 \times 10^{-5} \\
7 \times 10^{-6}\end{array}$ & $\begin{array}{l}81 \\
79 \\
82\end{array}$ & $\begin{array}{l}21 \\
16 \\
16\end{array}$ \\
\hline
\end{tabular}

oratory and measuring the resulting strain or change in vold ratio. A sample deforms very slow1y when loaded to stresses smaller than those it experienced in situ. When the load becomes greater than this value, the sample deforms more rapid1y. The maximum past overburden stress is therefore at a shoulder in a strain versus applied load curve. Consolidation tests upon two samples from core 5 both Indicated overconsolidation, as often occurs in samples taken a few meters below the sediment-water interface (Figure 6). Such apparent overconsolidation can be caused by erosion, by cementation, or by errors in determining the depth of the sample. Since this was a gravity core, the uppermost sediment was recovered, and errors in depth can be eliminated. (To support this concluston, we compare in Figure 7 the carbonate stratigraphy of this core with core 4. A1though the sedimentation rates are different, the ratios of depths to different horizons are equal, indicating that no sediment was lost from the top of core 5.) Erosion is more difficult to eliminate, since the low carbonate contents make age dating difficult. The peaks in carbonate content in cores 4 and 5 correspond when plotted against sample age. These ages were independently determined from local sediment thickness and basement age. The manganese content of core 5 also appears quite evenly distributed. This evidence suggests that no unconformities are present. Ce- 


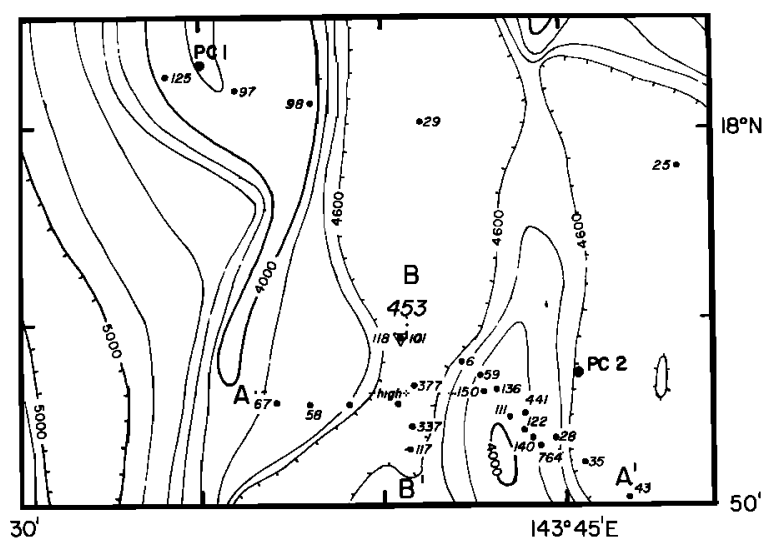

Fig. 4. Heat flow values in $\mathrm{mW} \mathrm{m}^{-2}$ in the vicinity of core 1 , core 2, and DSDP site 453 [Anderson et al., 1982]. Contour interval of topography is $200 \mathrm{~m}$.

mentation and downward water movement are therefore the two most probable causes of the overconsolidation of core 5 .

The rate of downward pore water advection needed to cause a given amount of overconsolidation is dependent upon the hydraulic conductivity (permeability) of the sediment and upon the buoyant weight of the sediment column. Consolidation tests indicated that a sample from a depth of $x$ of $219 \mathrm{~cm}$ in core 5 had a maximum past overburden pressure $\sigma_{x}$ of 125 to $300 \mathrm{~g} \mathrm{~cm}^{-3}$. The average buoyant density $\mathrm{Pb}$ of the sediment is estimated to be $0.44 \mathrm{~g} \mathrm{~cm}^{-3}$, so that the overburden pressure due to the buoyant weight of the sediment is estimated to be $96.4 \mathrm{~g} \mathrm{~cm}^{-2}$.

The range of pressure gradients $\nabla$ h can be calculated from the range of total overburden pressures, the density of water, and the buoyant density of the sediment:

$$
\sigma=\mathrm{Pb}_{\mathrm{b}} \mathrm{x}+\nabla \mathrm{h}_{\mathrm{w}} \mathrm{x}
$$

A range of pressure from 125 to $300 \mathrm{~m}$ of water yields pressure gradients from 0.13 to $0.90 \mathrm{~m}$ of water per meter. If we assume that the permeability $\mathrm{K}$ of the sediment is $4 \times 10^{-6} \mathrm{~cm} \mathrm{~s}^{-1}$ then the range of advection velocities, as calculated from Darcy's law is from $5.2 \times 10^{-7}$ to $3.6 \times 10^{-6} \mathrm{~cm} \mathrm{~s}^{-1}$. Although we cannot eliminate cementation as a possible cause of the overconsolidation in core 5 , the velocities estimated under this assumption are in general agreement with other measurements from the same region. Thermal measurements give advection velocities of about $1 \times 10^{-6}$ to $6 \times 10^{-6} \mathrm{~cm} \mathrm{~s}^{-1}$, with one value of $1 \times 10^{-5} \mathrm{~cm} \mathrm{~s}^{-1}$. Our permeability measurements upon Marianas sediments, both backpressured and nonbackpressured, indicate that the permeabilities (hydraulic conductivities) of the surface sediments range from $10^{-6}$ to $10^{-5} \mathrm{~cm} \mathrm{~s}^{-1}$ (Figure 8 , Table 3 ). The highest water velocities (as inferred from thermal measurements) are also about $10^{-5}$ to $10^{-6} \mathrm{~cm} \mathrm{~s}^{-1}$, implying that local pressure gradients in excess of

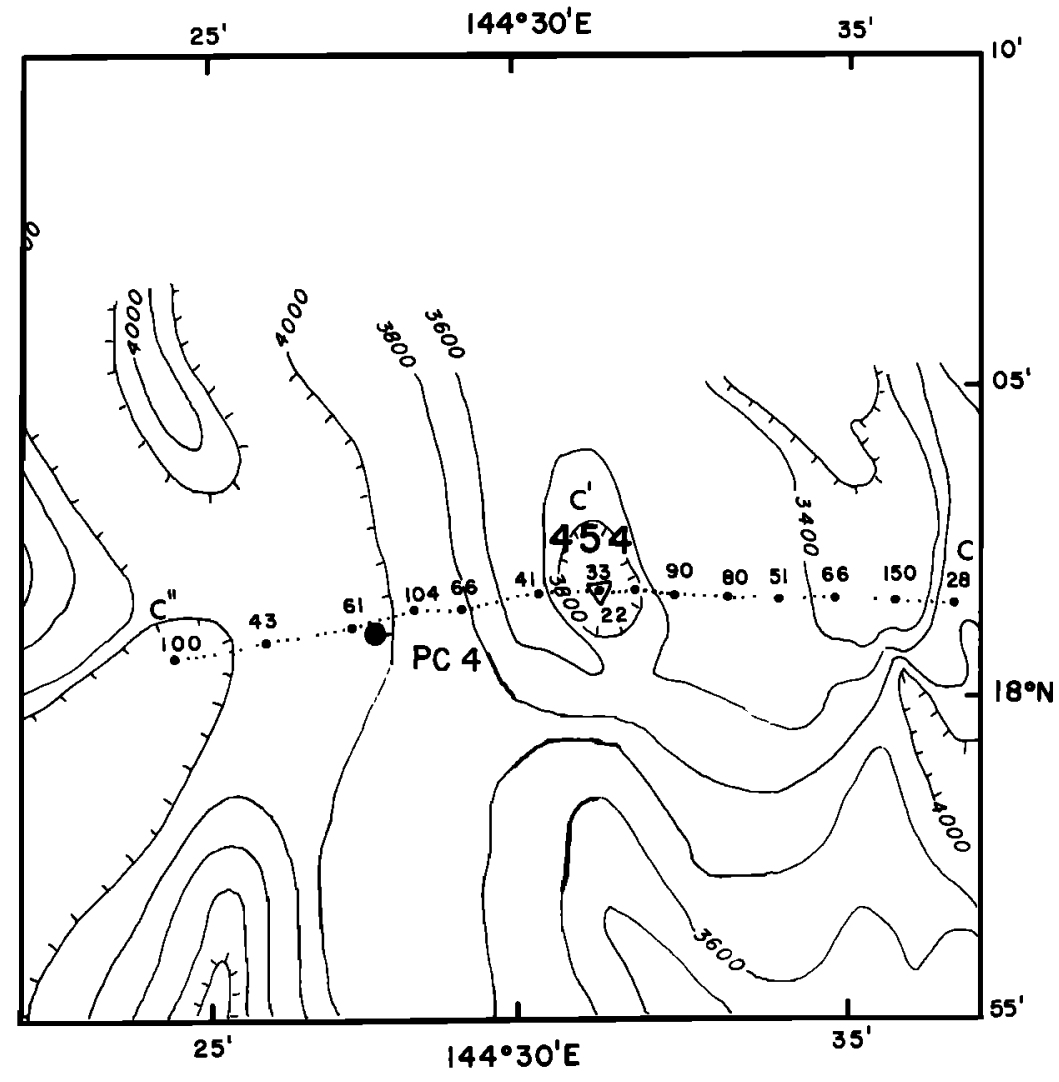

Fig. 5. Heat flow measurements in $\mathrm{mW} \mathrm{m}^{-2}$ in the vicinity of core 4 and DSDP site 454 [after Anderson et al., 1982]. The theoretical heat flow for this age oceanic crust is $250 \mathrm{~mW} \mathrm{~m} \mathbf{m}^{2}$. The heat flow measured during the DSDP leg was $22 \mathrm{~mW} \mathrm{~m}^{-2}$ [Uyeda and Horai, 1982]. Contour interval is $200 \mathrm{~m}$. 
$1 \mathrm{~m}$ of water per meter may occur. Such high-pressure gradients could occur locally in regions of downwelling water but would result in sediment slides in regions of upwelling water.

The importance of water circulation in the sediments is determined, in part, by the contrast in permeability between basalt and the sediment. Permeabilities of crystalline rocks are fracture controlled with in situ values from $10^{-7}$ to

$10^{-5} \mathrm{~cm} \mathrm{~s}^{-1}$ [Brace, 1980]. Deep-sea basalts have permeabilities in the higher part of this range [Brace, 1980; Anderson and Zoback, 1982]. Since the permeability of the upper sediments is as high as that of the basalt, a thin layer of sediment w111 have no more effect upon water circulation than the basalt itself.

One of the consolidation tests was accompanied by permeability measurements, which permit the estimation of the change in permeability caused by mechanical loading (Figure 8). If the permeability in the lower part of the sediment column is controlled by mechanical effects, then we can use these tests to estimate the permeability in the deeply burfed sediments. We can then model the change in variability of the thermal measurements caused by increasing sediment thickness. We assume that (1) most (but not all) of the varlability of the heat flow in young oceanic areas is caused by making measurements in sediments affected by water advection within them, (2) excess pore pressure in the basalt drives the water movement in the sediments, and (3) excess pore pressures in the basalt are not changed by increasing sediment thickness.

Using nonlinear thermal measurements as a guide [Anderson et al., 1982], we assume a maximum water velocity of $5 \times 10^{-6} \mathrm{~cm} \mathrm{~s}^{-1}$ in a sediment column $20 \mathrm{~m}$ thick. The average pressure gradient is assumed to decrease by a factor of 2 every time the sediment thickness doubles. The permeability of the basal sediment changes with increasing overburden pressure at the same rate as the sample from the consolidation test (Figure 6). The maximum water velocities for different sediment thicknesses and the resulting

\section{MARA 4 - CORE 5}

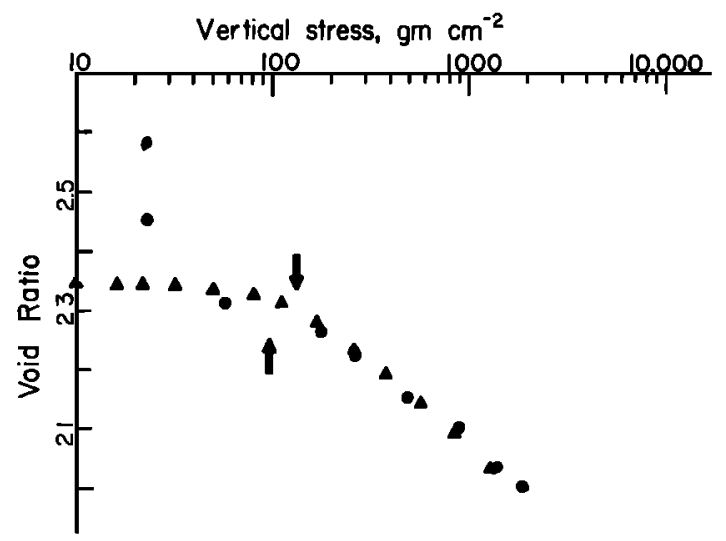

Fig. 6. Consolidation test results from core 5 . Circles are from the test of a sample 105-cm subbottom. Triangles are the results for a sample from $219-\mathrm{cm}$ subbottom. The upward pointing arrow shows the pressure at $219 \mathrm{~cm}$ due to the buoyant weight of the overlying sediment. The downward pointing arrow shows the minimum overburden pressure inferred from the consolidation test.
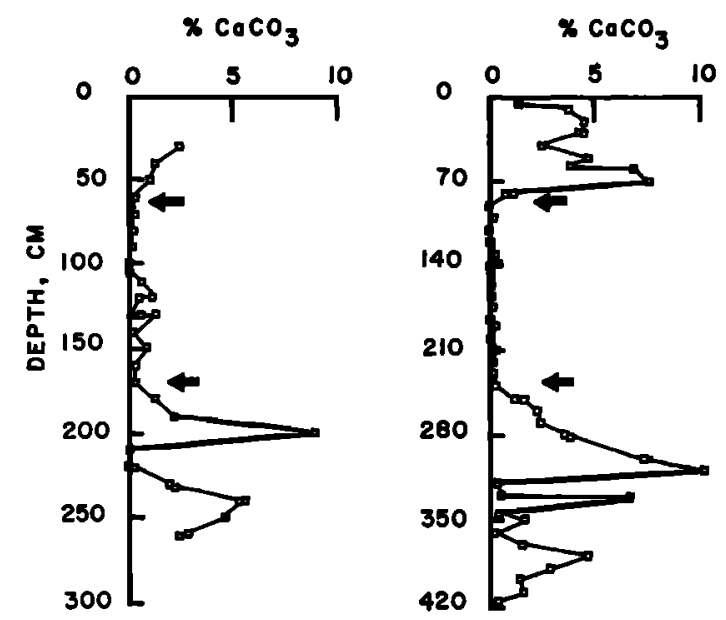

Fig. 7. Carbonate content for core 4 (right) and core 5 (left). Note that the ratios of depths of major stratigraphic horizons (arrows) are equal between cores, indlcating that the top of the cores were properly recovered. The overconsolidation of core 5 (see text) cannot be due to errors in determining sample depth.

maximum variability in measured thermal gradients are given in Table 4 . The maximum local pressure gradients are determined by the least permeable samples. Removal of sediment by sliding (due to local gradients $>1$ ) is predicted for areas with less than $40 \mathrm{~m}$ of sediment and rapid upwelling.

Some of the heat flow measurements from the Marianas were made over oceanic crust with a relatively small age range. Using profiler and 3.5-kHz precision depth records, the sediment thickness at each thermal measurement site can be estimated. The theoretical heat flow from crust of this age (1.24 to $3.2 \mathrm{m.y.}$ ) ranges from 280 to $459 \mathrm{~mW} \mathrm{~m}^{-2}$. The actual range in heat flow is from 22 to $2084 \mathrm{~mW} \mathrm{~m}^{-2}$, far higher than any variation predicted by the range of ages. The maximum variability in heat flow predicted by topographically driven hydrothermal circulation in the basalt alone is a factor of 13 [Gartling and Anderson, 1982]. Age differences and topographic effects together are still not sufficient to explain the 2 orders of magnitude variation in the measured heat flow. Using an average heat flow of $200 \mathrm{~mW} \mathrm{~m}^{-2}$, we have determined the estimated maximum variability of heat flow with increasing sediment thickness from our model (Figure 9). We plot the maximum variability predicted from our model with all the heat flow measurements from 1.2 to $3.2 \mathrm{~m} . \mathrm{y}$. crust in the Marianas. Eighty-seven percent of the heat flow measurements lie within the bounds predicted by this simple model. The remainder of heat flow variability is small enough to result from topographic effects.

The fact that most of the heatflow varlability in this area of young oceanic crust must be due to water circulation within the sediment column has important implications. Lawrence and Gieskes [1981] estimated that water advection continues in the basalt until subduction on the basis of oxygen isotope data. If so, excess pore pressures w111 also persist in the basalt. Evidence that such excess pore pressures do continue to exist even in 


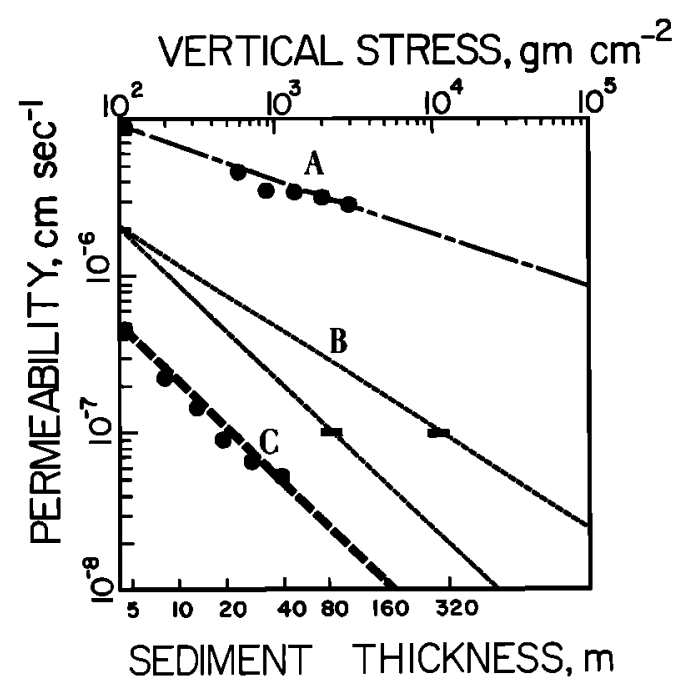

Fig. 8. Change of permeability caused by the increasing welght of overlying sediments (for lines $A$ and $B$ ). Circles on line $A$ are the results from a consoldiation-permeability test on a sample from 105-cm depth in core 5. The circles on line C are consolidation-permeability results for a sample from the central Pacific [Nickerson, 1975]. The two lines at $B$ are extrapolated permeability changes with increasing sediment thickness for the least permeable Marianas sample.

areas w1th heat flow equal to the theoretical value is the underpressure ( $2 \%$ below hydrostatic) measured in the basalt of the Galapagos beneath a sediment column $275 \mathrm{~m}$ thick [Anderson and Zoback, 1982]. Our simple model of water circulation in the sediment column predicts that increasing sediment thickness damps water circulation in the sediments, with no need for any reduction in the driving force behind the water movement. If the excess pore pressure in the basalt exists, water circulation in the sediments may continue in locations with thin sediment cover even in the oldest oceanic crust. The extent of water circulation in the regions with thin sediment cover can be constrained by calculating the amount of contact with bottom water that can be tolerated without reducing the heat flow below theoretical. Unfortunately, we do not have sufficient information to make this calculation. Another important consideration is the extent to which diagenesis rather than compaction changes the permeability of the basal sediment. However, even without this data we can derive information about the sediment thickness necessary to impede water circulation in the sediment.

\section{Sealing Thickness From Pore Water Data}

If all chemical gradients are assumed to result from reactions in the basalt, with the sediments acting as a passive boundary layer, then water advection rates higher than about $10^{-8} \mathrm{~cm} \mathrm{~s}^{-1}$ w111 cause uniform pore water compositions except in the vicinity of the sediment-water interface (upwelling water) or sediment-basement interface (downwelling water [Bredehoeft and Papadopulos, 1965]. However, if reactions between the pore water and the sediments occur, then the advection rates needed to cause uniform pore water compositions will be at least an order of magnitude higher.

As we discussed earlier, the anomalies in pore water $\mathrm{Ca}, \mathrm{Mg}, \mathrm{LI}$, and $\mathrm{Sr}$ at DSDP sites 453,458 ,

TABLE 3. Pore Water Data Uncorrected for Squeezing Artifacts

\begin{tabular}{|c|c|c|c|c|c|c|c|}
\hline Core & $\begin{array}{l}\text { Depth } \\
\text { Range } \\
\mathrm{cm}\end{array}$ & $\begin{array}{l}\text { Center } \\
\text { Depth } \\
\text { cm }\end{array}$ & $\mu \mathrm{M} 1^{-1}$ & $\mu M^{L 1} 1^{-1}$ & $\mu M^{S 1} 1^{-1}$ & $\begin{array}{c}\mathrm{Ca}_{\mathrm{I}^{-1}} \\
\mathrm{mM}\end{array}$ & $\underset{\mathrm{mM}}{\mathrm{Mg}}{ }^{-1}$ \\
\hline $\mathrm{C} 1$ & $\begin{array}{c}70 / 78 \\
135 \\
239 \\
280 / 290\end{array}$ & $\begin{array}{r}75 \\
135 \\
239 \\
285\end{array}$ & $\begin{array}{r}3.1 \\
6.6 \\
9.4 \\
10.9\end{array}$ & $\begin{array}{l}25.2 \\
26.4 \\
27.0 \\
31.9\end{array}$ & $\begin{array}{l}607 \\
530 \\
578 \\
562\end{array}$ & $\begin{array}{l}10.86 \\
11.28 \\
12.05 \\
12.33\end{array}$ & $\begin{array}{l}48.9 \\
48.6 \\
48.2 \\
49.6\end{array}$ \\
\hline $\mathrm{C} 4$ & $\begin{array}{c}67 / 77 \\
227 / 238 \\
329 / 335 \\
513 / 519 \\
654 / 660 \\
812 / 818\end{array}$ & $\begin{array}{r}72 \\
232 \\
332 \\
516 \\
657 \\
815\end{array}$ & $\begin{array}{l}0 \\
0 \\
2.8 \\
0 \\
0 \\
0\end{array}$ & $\begin{array}{l}25.2 \\
25.2 \\
26.4 \\
27.0 \\
27.6 \\
27.6\end{array}$ & $\begin{array}{l}562 \\
546 \\
534 \\
490 \\
524 \\
464\end{array}$ & $\begin{array}{l}10.55 \\
10.49 \\
10.66 \\
10.07 \\
10.44 \\
10.44\end{array}$ & $\begin{array}{l}51.4 \\
50.5 \\
50.9 \\
49.3 \\
49.7 \\
51.6\end{array}$ \\
\hline $\mathrm{C} 5$ & $\begin{array}{c}00 / 06 \\
159 / 169 \\
280 / 290\end{array}$ & $\begin{array}{r}3 \\
163 \\
285\end{array}$ & $\begin{array}{c}0 \\
3.6 \\
12.2\end{array}$ & $\begin{array}{l}27.0 \\
27.6\end{array}$ & $\begin{array}{l}323 \\
420 \\
445\end{array}$ & $\begin{array}{r}10.09 \\
9.87 \\
11.07\end{array}$ & $\begin{array}{l}49.4 \\
48.9 \\
47.8\end{array}$ \\
\hline$c 7$ & $\begin{array}{l}410 / 416 \\
511 / 518\end{array}$ & $\begin{array}{l}413 \\
515\end{array}$ & $\begin{array}{l}0 \\
0\end{array}$ & $\begin{array}{l}27.6 \\
27.0\end{array}$ & $\begin{array}{l}316 \\
309\end{array}$ & $\begin{array}{l}10.44 \\
10.05\end{array}$ & $\begin{array}{l}51.3 \\
49.8\end{array}$ \\
\hline $\mathrm{C} 8$ & $\begin{array}{c}42 / 48 \\
112 / 118 \\
192 / 198\end{array}$ & $\begin{array}{r}45 \\
115 \\
195\end{array}$ & $\begin{array}{l}0 \\
0 \\
0\end{array}$ & $\begin{array}{l}29.0 \\
30.2 \\
30.9\end{array}$ & $\begin{array}{l}320 \\
368\end{array}$ & $\begin{array}{l}10.22 \\
10.13 \\
10.23\end{array}$ & $\begin{array}{l}51.2 \\
50.0 \\
51.0\end{array}$ \\
\hline \multicolumn{2}{|c|}{ Seawater } & & 0 & 26.8 & 160 & 10.46 & 53.5 \\
\hline
\end{tabular}


TABLE 4. Surface Heat Flow determined From Temperature Gradient at 5-m Depth for Downwelling Water and 5-cm Depth for Upwelling Water

\begin{tabular}{|c|c|c|c|c|c|}
\hline \multirow{2}{*}{$\begin{array}{l}\text { Sediment } \\
\text { Thickness } \\
\quad \text { m }\end{array}$} & \multirow{2}{*}{$\begin{array}{l}\text { Maximum } \\
\text { Water } \\
\text { Velocity, } \\
\mathrm{cm} \mathrm{s}^{-1}\end{array}$} & \multirow{2}{*}{$\begin{array}{l}\text { Thermal } \\
\mathrm{V}_{\mathrm{p}} \mathrm{Up}, \\
\mathrm{K} \mathrm{m}^{-1}\end{array}$} & \multirow{2}{*}{$\begin{array}{c}\text { Gradient } \\
\begin{array}{r}\text { Vp Down, } \\
K \mathrm{~m}^{-1}\end{array}\end{array}$} & \multicolumn{2}{|c|}{ Heat Flow } \\
\hline & & & & 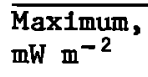 & $\begin{array}{l}\text { Minimum, } \\
\mathrm{mW} \mathrm{m^{-2 }}\end{array}$ \\
\hline $\begin{array}{r}20 \\
40 \\
60 \\
100 \\
200 \\
400\end{array}$ & $\begin{array}{l}5.0 \times 10^{-6} \\
1.1 \times 10^{-6} \\
7.2 \times 10^{-7} \\
4.0 \times 10^{-7} \\
1.15 \times 10^{-7} \\
2.5 \times 10^{-8}\end{array}$ & $\begin{array}{l}4.9 \\
2.5 \\
2.4 \\
2.3 \\
1.6 \\
1.27\end{array}$ & $\begin{array}{l}0.034 \\
0.27 \\
0.34 \\
0.35 \\
0.53 \\
0.77\end{array}$ & $\begin{array}{r}1000 \\
480 \\
480 \\
460 \\
320 \\
254\end{array}$ & $\begin{array}{r}7 \\
54 \\
68 \\
70 \\
106 \\
154\end{array}$ \\
\hline
\end{tabular}

Thermal diffusivity $=0.002 \mathrm{~cm}^{2} \mathrm{~s}^{-1}, Q_{\mathrm{av}}=200 \mathrm{~mW} \mathrm{~m} \mathrm{~m}^{-2}$.

and 459 appear to be greatest some distance above the sediment-basement interface and are small near the basement. This observation, coupled with the fact that the total magnitude of compositional changes is greater than the differences from seawater in known basaltic pore waters, indicates that some chemical reactions are occurring within the sediment column. A sample calculation using results derived in more detail in the appendix indicates the extent to which even small rates of reaction in the sediment column increase the advection rate needed to produce uniform pore water compositions.

For a dissolution reaction with a linear rate constant, the equation describing the concentration with depth is

$$
\delta(x)=\delta_{0} \exp (-g x)
$$

where $\delta$ is the difference between the saturation and the actual concentration, $x$ is depth, and $\delta=\delta(x=0)$. The constant $g$ is given by

$$
g=\frac{\left[v^{2}+4 K E\right]^{1 / 2}-v}{2 K}
$$

where $E$ is a constant that contains the dissolution rate in the sediment, $K$ is the chemical diffusion coefficient, and $v$ is the advection rate. Both $E$ and $K$ are positive numbers, but $v$ may be positive or negative in sign. When $v$ is small, the exponential is convex upward, approaching the saturation concentration at great depths. However, when $v$ is large and positive (downward advection), then $g$ is numerically very small, so that the concentration will vary almost Iinearly in the upper part of the sediment column. Conversely, when $v$ is negative (upward advection), $g$ is numerically very large, and the saturation concentration will be reached at shallow depths.

In the absence of advecting pore water, the constant $g$ can be calculated from the following parameters: the area per unit volume of sediment grains, which for a typical marine sediment is about $8000 \mathrm{~cm}^{-1}$; the weight fraction of reacting material, which we assume to be quite small, $1 \%$ since the sediments are diluted with terrigenous material; the saturation concentration and rate constant, which in the case of silica are about
$0.6 \mu \mathrm{M} \mathrm{cm}-3$ and $4 \times 10^{-6} \mathrm{~cm}^{2} \mathrm{~s}^{-1}$, and a dissolution coefficient of about $8.4 \times 10^{-8} \mu \mathrm{M} \mathrm{cm} \mathrm{cm}^{-2} \mathrm{~s}^{-1}$ [Schink et al., 1975]. A significant advection rate might be one that doubled the value of the constant $g$. For the above parameters, this velocity is $2.7 \times 10^{-6} \mathrm{~cm} \mathrm{~s}^{-1}$. This water velocity is higher than the minimum advection velocity needed to affect heat flow measurements, about $10^{-8} \mathrm{~cm} \mathrm{~s}^{-1}$.

A particle of biogenic silica which dissolved at the rate used in the preceding calculation would have an average residence time in the sediment of about 30 years [Schink et al., 1975]. More geologically significant would be particles with residence times of a few hundred thousand to millions of years. Such a particle would require a dissolution rate constant orders of magnitude lower. For Instance, if in the above calculation the rate constant is reduced by 4 orders of magnitude, the doubling velocity is lowered to $2.7 \times 10^{-8} \mathrm{~cm} \mathrm{~s}^{-1}$. If the dissolving species made up more than $1 \%$ of the sediment, then the doubling velocity might be higher, as high as $3 \times 10^{-7} \mathrm{~cm} \mathrm{~s}^{-1}$.

The water velocity necessary to affect chemical gradients in sediments acting as a passive boundary layer would be about $10^{-9} \mathrm{~cm} \mathrm{~s} \mathrm{~s}^{-1}$ in sediments tens of meters thick and $10^{-10} \mathrm{~cm} \mathrm{~s}^{-1}$ in sediment hundreds of meters thick. The advection velocities needed to completely remove the gradients would be

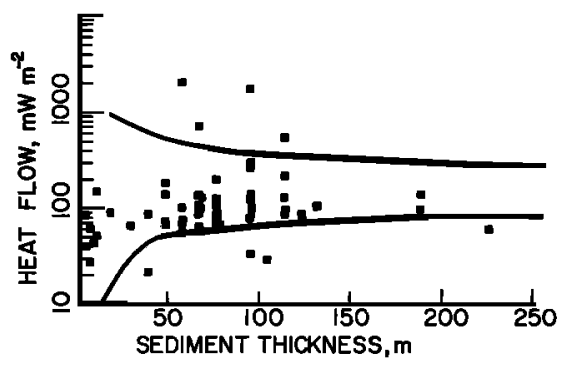

Fig. 9. Heat flow in $\mathrm{mW} m-2$ [after Anderson et al., 1982] versus sediment thickness in meters for the oceanic crust near site 454 and just west of site 454 in the Marianas. The black bounding lines are the maximum and minimum values of heat flow that should result from water advection through the sediments. As sediment thickness increases, decreasing permeability and pressure gradients reduce the maximum variability in the heat flow. 
about an order of magnitude higher than these values. The result of our calculations indicate that even very slow chemical reactions can change the estimate of advection velocity by at least an order of magnitude. If this is true, then the range of water velocities needed to produce nonlinear thermal profiles and to erase chemical gradients are about the same $\left(10^{-7} \mathrm{~cm} \mathrm{~s}^{-1}\right)$. In the case of rapid reactions, thermal measurements may even be affected at lower advection rates than those needed to change significantly pore water compositions.

\section{Advection in Thick Sediments}

The only core with pore water chemistry that indicated advection too slow to remove chemical gradients was core 1 . The gradient of $\mathrm{Ca}$ in this core was $0.66 \mathrm{mM} \mathrm{m}^{-1}$, much higher than the average calcium gradients at DSDP sites 453,458 , and 459 , which ranged from 0.1 to $0.15 \mathrm{mM} \mathrm{m}^{-1}$. If the sediments are acting as a passive boundary layer near core 1 , then the upward advection rate needed to produce this increase in surface chemical gradient is quite slow. However, if reactions are occurring within the sediments, then upward advection rates would need to be much higher to produce the same response. We cannot estimate the advection rate because we do not know how fast $\mathrm{Ca}$ is added to the pore water. Our other gravity cores were from locations with less than $40 \mathrm{~m}$ of sediment, so that the lack of chemcial gradients is not surprising. DSDP data from the Marianas show chemical gradients in $\mathrm{Ca}$ and $\mathrm{Mg}$ at sites 453 and 456 with respective sediment thicknesses of 67 and $140 \mathrm{~m}$. Sites 454 and $456 \mathrm{~A}$, with sediment thicknesses of 67 and $120 \mathrm{~m}$, lacked chemical gradients in $\mathrm{Ca}$ and $\mathrm{Mg}$ [Gieskes and Johnson, 1982]. The sediment thicknesses necessary to cause advection to slow sufficiently for chemical gradients in $\mathrm{Ca}$ and $\mathrm{Mg}$ to form would therefore appear to be in the range of 100 to $120 \mathrm{~m}$ in the Mariana Trough.

\section{Heat Flow and Sealing Thickness}

The maximum sediment thickness at any location in the Marlanas with a nonlinear thermal profile is about $100 \mathrm{~m}$. The sediment thickness at which the local variability in heat flow is small enough to result from topographic effects is around $120 \mathrm{~m}$ (Figure 8). The heat flow at DSDP site 456 is twice the heat flow at site 456A [Uyeda and Horai, 1982]. If this difference is due to downward water advection in the sediments at site $456 \mathrm{~A}$, then these data are consistent with the lack of chemical gradients in $\mathrm{Ca}$ and $\mathrm{Mg}$ at site $456 \mathrm{~A}$ and the presence of chemical gradients at site 456 . The fastest water velocity that could erase the chemical gradients at site $456 \mathrm{~A}$ and that also fits the passive boundary layer model is $3 \times 10^{-8} \mathrm{~cm} \mathrm{~s}^{-1}$. The slowest water velocity that would produce the observed difference in heat flow between the two sites is about $3 \times 10^{-7} \mathrm{~cm} \mathrm{~s}^{-1}$. Although some of the difference in heat flow between the two sites can be attributed to a change in the basement temperature, the $200 \mathrm{~m}$ distance between the two drill sites suggests that little of the anomaly could be due to difference in basement temperature. Pore water and thermal data from sites 456 and $456 \mathrm{~A}$ would be inconsistent unless some chemical reactions are occurring in the sediment column.

Thermal and chemical data together suggest that water circulation in the sediments is definitely present in locations with less than $100 \mathrm{~m}$ of sediment in the Marianas. These sediments are largely composed of volcanic glass and are fine grained and prone to alteration. The results from mode1ing thermal and physical property measurements imply that thermally significant water advection may continue in sediments up to $100 \mathrm{~m}$ thick. The thermal indications of advection in the thick sediments are difficult to reconcile with pore water data if the sediments do indeed act only as a passive boundary layer. Calculations indicate that even very slow chemical reactions may increase advection velocities needed to affect thermal measurements. These results indicate that a sediment thickness of 100 to $120 \mathrm{~m}$ is a conservative estimate of the thickness needed to seal thermally and chemically the hydrothermal systems in the Mariana Trough.

\section{Water Circulation and Carbonate Dissolution}

We have developed a mathematical model of the effects of water advection in the sediment column upon the dissolution of calcium carbonate (see the appendix).

Our model 1gnores the effects of biogenic activity upon dissolution. We have considered the homogenizing effect of biologic activity upon the upper $10 \mathrm{~cm}$ of sediment, but we find that it does not greatly affect our results.

The major factors that affect carbonate dissolution are the degree of undersaturation of the pore water with respect to carbonate ion, the amount of exposed surface area of the carbonate fraction of the sediment, the rate of dissolution of carbonate for a given undersaturation, and the extent of transport of carbonate ion by advection and diffusion. We will examine the effects of the first three factors for the case where only diffusion is important and then consider the effect of advection upon the system.

The rate of dissolution of carbonate is a power function of the carbonate undersaturation of the surrounding water. The exponent of the power function is suggested by the results of Morse [1978] to be about 5 and by that of Takahashi and Honjo [1982] to be between 3 and 4 .

Since the exponent of the dissolution function is poorly known, we examine how different exponents affect the depth range over which dissolution occurs (Figure 10a, Table 5). We describe the amount of dissolution by the'cumulative dissolution,' that is, the amount of carbonate dissolved from the sediment column per unit time between the sediment-water interface and a given depth. In these calculations we have chosen the other parameters so that the cumulative dissolution at very great (infinite) depth is the same regardless of exponent. The larger exponents can then be seen to have the effect of concentrating the dissolution at the top of the sediment column.

The amount of dissolution is also influenced by the degree of undersaturation of the bottom water with respect to carbonate. This effect is evident in calculations shown in Figure 1la (Table 5) where we have used the dissolution function of Morse [1978]. As the undersaturation of the bottom water increases, the subbottom depth where half the dissolution has occurred moves from about $1 \mathrm{~cm}$ to less than $1 / 2 \mathrm{~cm}$. This is a conservative estimate, 
since the instantaneous dissolution does not take into account the decreasing sedimentation rate in the upper few centimeters of sediment that is the direct result of dissolution. We will discuss the effects of this volume loss of carbonate upon total dissolution later.

The available surface area of carbonate per unit volume of sediment is the third major variable affecting dissolution. The available surface area per unit volume of carbonate is largely a function of the grain size distribution of the sediment. Most of the available area is concentrated in the smallest particles. We assume that the maximum available surface area is the surface area measured by Morse [1978] for an Indian Ocean sediment which had an unusually large fraction of fine carbonate particles. Morse [1978] also measured the surface area for the $>63 \mu$ fraction of the sediment and found it to be about 10 times the surface area of solid calcite spheres with the same diameter. We assume that the surface area of the whole sediment is also ten times that of the equivalent calcite spheres. A sediment with a grain size distribution that would produce the surface area measured by Morse [1978] would be about 30\% coccoliths [Honjo, 1977]. We assume that the grain size distribution of the carbonate fraction of the sediment is normally distributed in $\phi=1 n_{2} d$, where $d$ is the diameter. A normal distribution of sizes is close to some actual distributions, although in some cases a bimodal normal curve might be more appropriate [Theide, 1977].

For low cumulative distributions, the grain size distribution of the carbonate will remain fixed. However, at some critical undersaturation a significant fraction of the surface sediment will dissolve before it is buried. The dissolution of the carbonate should be preferentially concentrated in the smallest particle sizes since these particles have the greatest surface area to volume ratio. Most of the dissolution will occur on the bottom

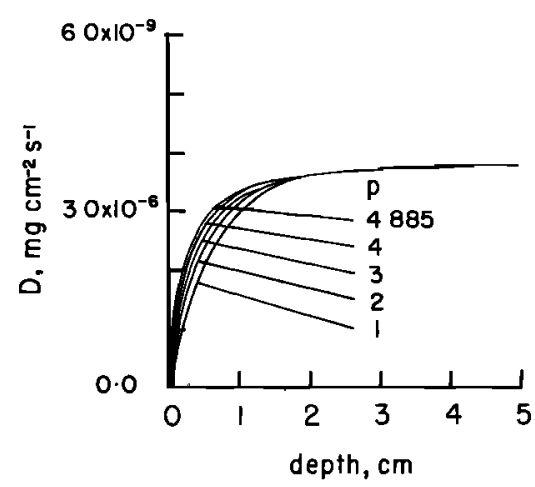

Fig. 10a. Cumulative dissolution D of cárbonate ions as a function of depth in the sediment column for several different dissolution functions. Carbonate transport is by diffusion only, since the advection velocity is zero. The dissolution functions have exponents $p$ equal to 1.1-4.835. The higher end of this range is most representative of experimental results. The coefficient a of the dissolution function has been chosen so that the cumulative dissolution at infinity for all five cases is the same. Note that the dissolution becomes concentrated near the surface as the exponent increases. See Table 5 for a list of parameters used in calculations.

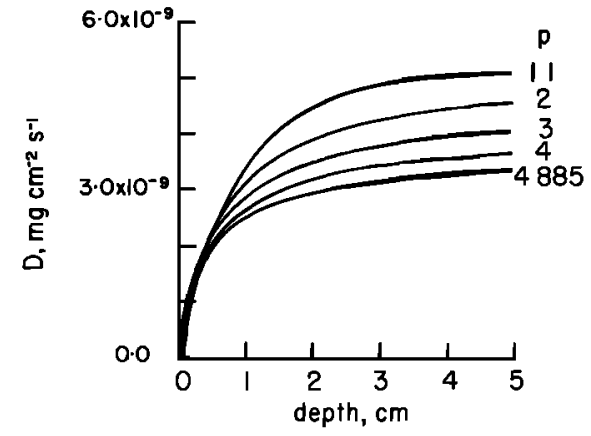

Fig. 10b. Cumulative dissolution D of carbonate ions as a function of depth in the sediment column for several different dissolution functions. Carbonate transport is mainly by advection, since the advection velocity is $5.0 \times 10^{-6} \mathrm{~cm} \mathrm{~s}^{-1}$. The dissolution functions have exponents equal to $1.1-$ 4.885. The higher end of this range is most representative of experimental results. The coefficient a of the dissolution function has been chosen to be the same as in Figure 10a. Note that significant dissolution occurs at correspondingly greater depths as the exponent is increased. See Table 5 for list of parameters used in calculations.

rather than in the water column [Honjo, 1977]. The grain size distribution of the carbonate fraction of the subsurface sediment should be a direct reflection of the undersaturation of the bottom water. Biologic productivity and burial rate by noncarbonate debris will affect the residence time of the particle at the sediment-water interface.

Uncertalnties about the surface area of the carbonate fraction of the sediments and the actual form of the dissolution function are the major 1imitations of our model. Predictions of increased or decreased dissolution due to different effects are certainly correct, but we are unable to predict the absolute carbonate percentage for a given location.

Another important variable affecting dissolution rates is the amount of dilution of siliceous and carbonate material by terrigenous debris. We assume that blologic productivity for a given small area is constant and that only the dilution of carbonate by other materials contributes to changes in the initial carbonate content of the sediment. This increased dilution decreases the time that a particle spends near the surface of the sediment. Figure 12a (Table 6) shows the effect of differing residence times near the surface for different initial dilutions. The total dissolution is not changed much by initial dilution, with the final carbonate contents of the sediment varying from 0.96 to $8.6 \%$ from initial values of 1 to $10 \%$. This range of inttial carbonate content is typical of the Marianas area. Knowledge of the total sedimentation rate is important in determining if the carbonate content of the sediment is low.

The effect of water advection upon carbonate dissolution is shown in Figures $10 \mathrm{~b}, 11 \mathrm{~b}, 12 \mathrm{~b}$, and 13. Water advection changes the size of the region of the sediment in which most of the dissolution occurs from about $2 \mathrm{~cm}$ to more than $10 \mathrm{~cm}$ from downward advection. Conversely, upward advecting saturated water will decrease the thickness of the zone in which carbonate dissolution occurs. Since the zone of bioturbation is estimated to be 
TABLE 5. Parameters Used in Model Calculations in Figures 10 and 11

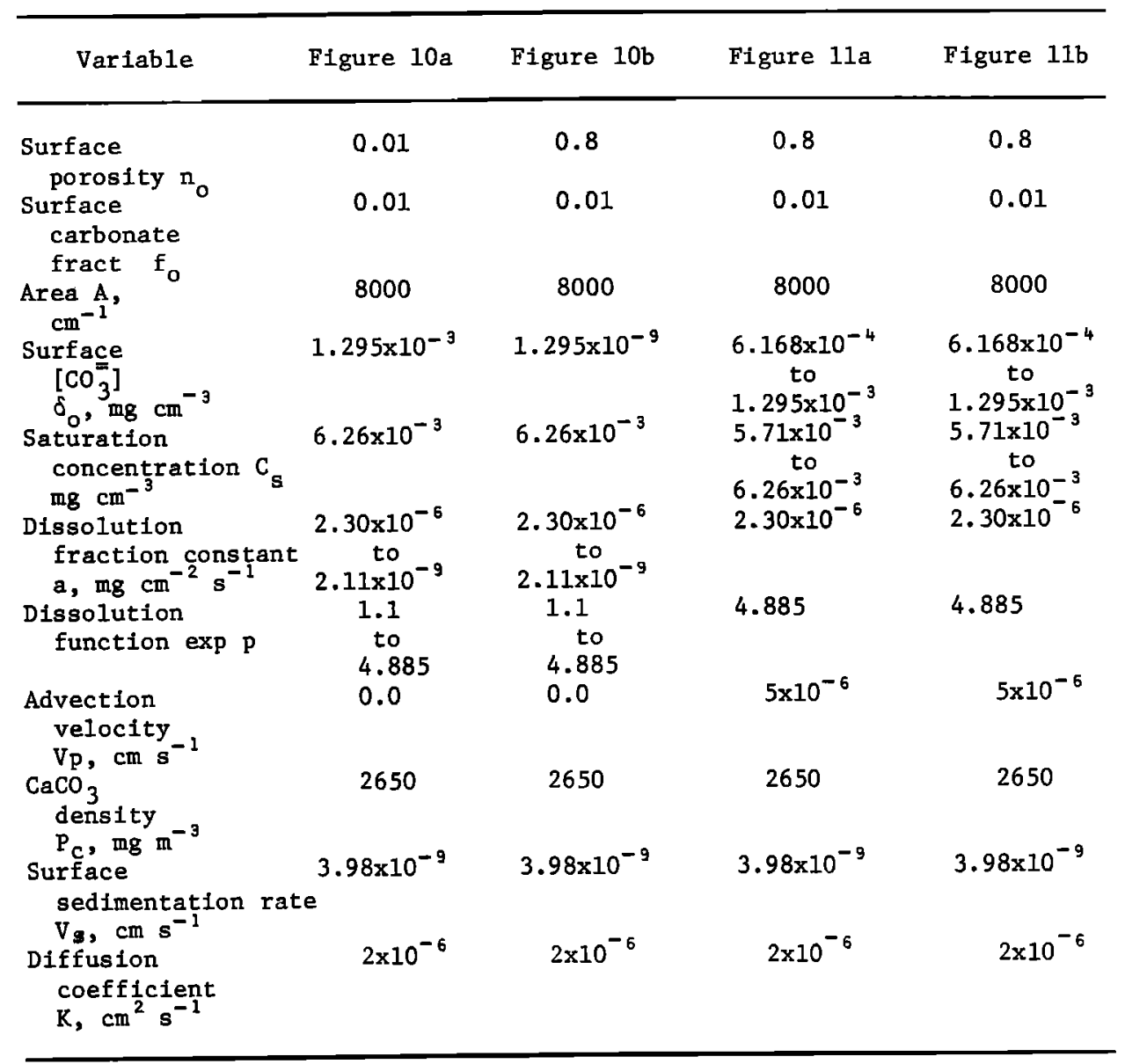

4 to $10 \mathrm{~cm}$ thick, upward water advection or no advection will have no effect upon the sharpness of carbonate fluctuations produced by changes in climate. Conversely, rapid downward advection in the range from $1 \times 10^{-6}$ to $5 \times 10^{-6} \mathrm{~cm} \mathrm{~s}^{-1}$ could af-

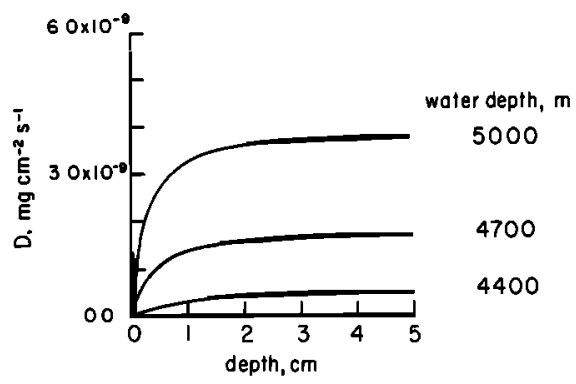

Fig. 11a. Cumulative dissolution $D$ of carbonate ion as a function of depth in the sediment column for several different water depths. Carbonate transport is due entirely to diffusion, since the advection velocity is taken to be zero. In any given region of the ocean the saturation concentration and degree of undersaturation of the bottom water will vary with the water depth [Takahashi et al., 1980]. These parameters have been chosen to model the dissolution if the sedimentwater interface is located at the given depths. Note that the amount of dissolution increases as the water depth increases. See Table 5 for list of parameters used in calculations. fect not only. the carbonate preservation in the climatic signal but also upon the relative sharpness of the high carbonate peaks. The range of water velocities observed in the Marianas could cause increases or decreases in the rate of car-

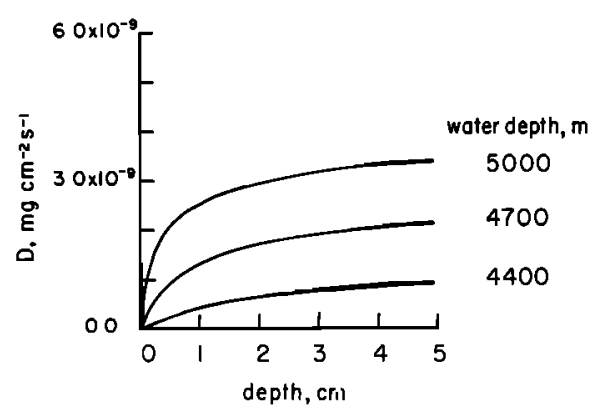

Fig. 11b. Cumulative dissolution D of carbonate ion as a function of depth in the sediment column for several different water depths. Carbonate transport is mainly by advection, since the advection velocity is $5.0 \times 10^{6} \mathrm{~cm} \mathrm{~s} \mathrm{~s}^{-1}$. In any given region of the ocean the saturation concentration and degree of undersaturation of the bottom water will vary with depth [Takahashi et al., 1980]. These parameters have been chosen to model the dissolution if the sediment-water interface is 1ocated at the given depths. See Table 5 for list of parameters used in calculations. 
TABLE 6. Parameters Used in Model Calculations in Figures 12 and 13

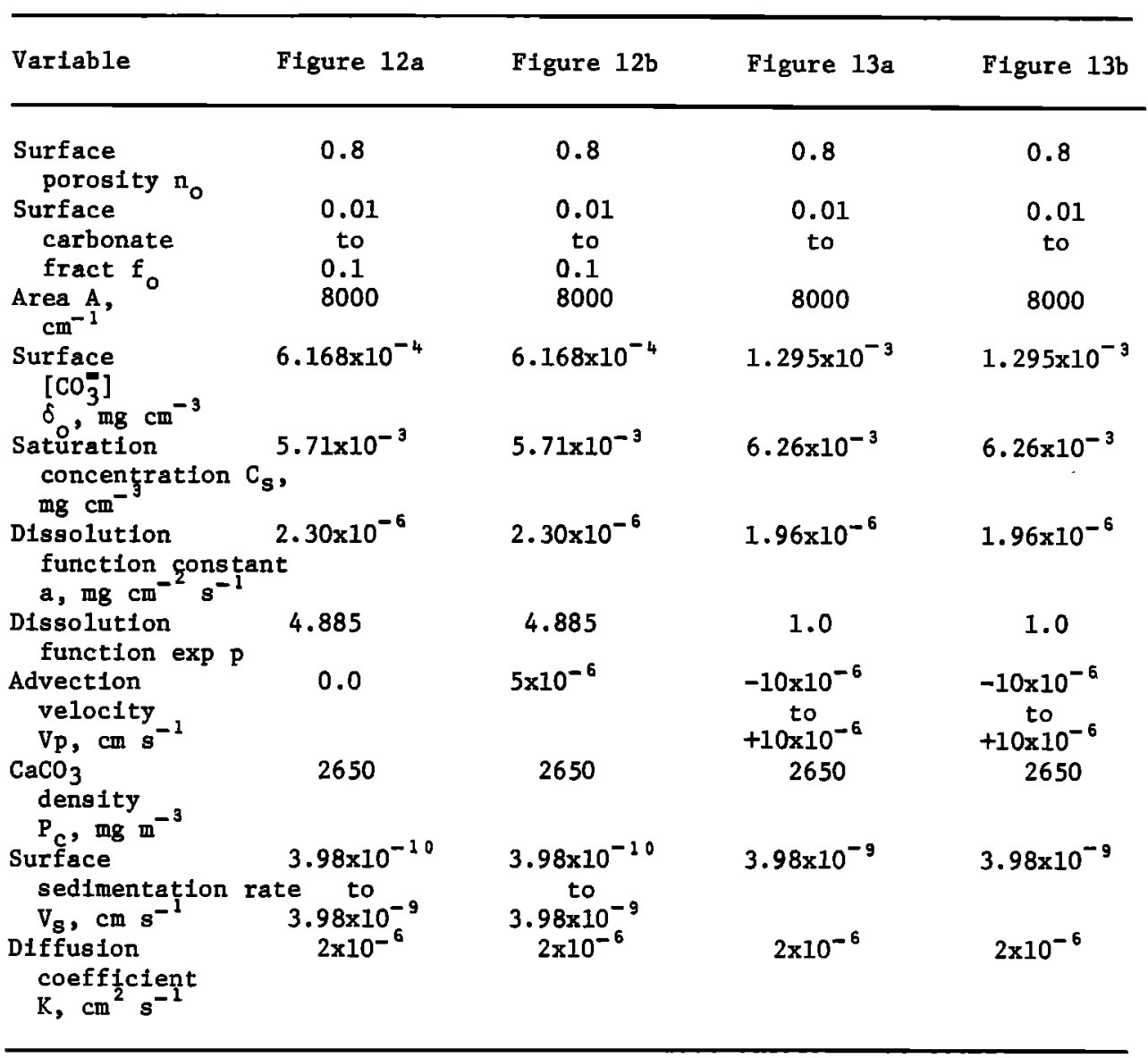

bonate dissolution of a factor of 5 (Figure 13a, Table 6). Evidence that such effects are occurring in the Marianas is the fact that all of the cores with downward water movement predicted from pore water and physical property measurements (cores 5, 7, and 8) have an average carbonate con-

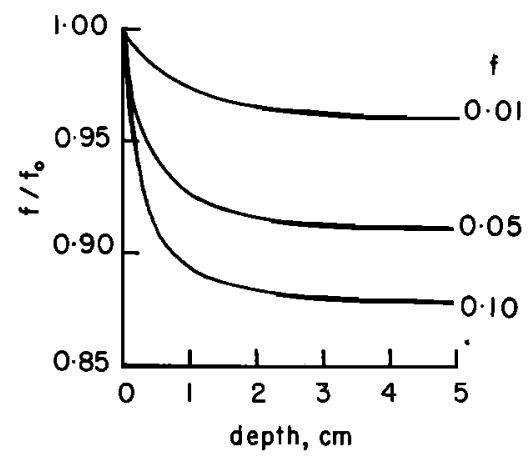

Fig. 12a. Normalized fraction of calcium carbonate $f / f_{o}$ as a function of depth in the sediment column for several different surface calcium carbonate fractions $f_{p}$. Note that the more calcium carbonate is initially present in the sediment, the more quickly calclum carbonate is lost with depth. Carbonate transport is entirely due to diffusion, since the advection velocity is taken to be zero. See Table 6 for list of parameters used in calculations. tent of $1 \%$ or less. The cores w1th upward water movement or no water movement (cores 1 and 4) have an average carbonate content of $2-4 \%$. Our method of carbonate analysis is accurate to $0.1 \%$, and we have averaged the carbonate contents for the same age range in all cores. Although some of the differences may be attributed to water depth or dilution effects, a comparison between cores 4 and 5 is quite convincing. The two cores have nearly

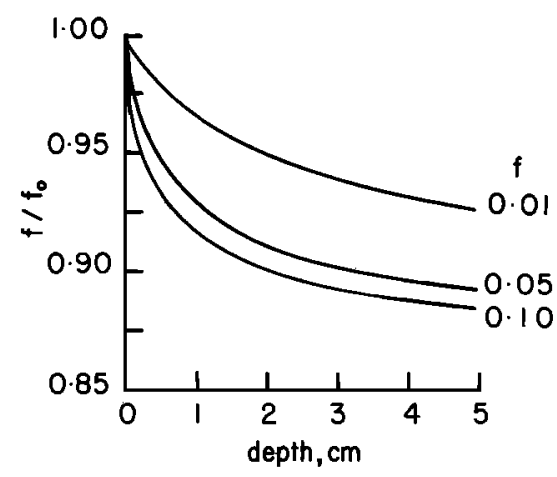

Fig. 12b. Normalized fraction of calcium carbonate, $f / f_{o}$ as a function of depth in the sediment column for several different surface calcium carbonate fractions $f_{o}$. Transport of carbonate is mainly by advection, since the advection velocity is $5.0 \times 10^{-6} \mathrm{~cm} \mathrm{~s}^{-1}$. See Table 6 for list of paramaters used in calculations for all exponents. 


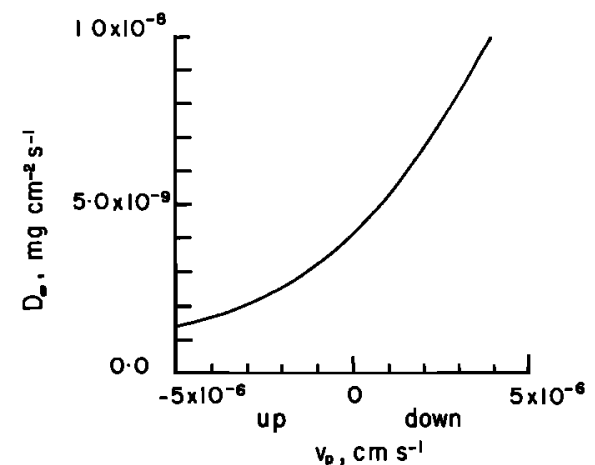

Fig. 13a. Cumulative dissolution at infinity Doo (in practice about $20 \mathrm{~cm}$ ) of carbonate ion as a function of advection velocity $v_{p}$ for a linear function $(p=1)$. Negative velocities are upward, while positive velocities are downward. Note that about 10 times as much carbonate is dissolved for a downward velocity of $1.0 \times 10^{-5} \mathrm{~cm} \mathrm{~s}^{-1}$ than for an upward advection velocity of $1.0 \times 10^{-5} \mathrm{~cm} \mathrm{~s}^{-1}$. See Table 6 for a list of parameters used in calculations.

identical sedimentation rates, so dilution effects should be the same. Core 5 is in $3876 \mathrm{~m}$ of water where the bottom water has about half the undersaturation which is present at the $4142 \mathrm{~m}$ depth of core 4. The advection rates predicted for both cores are in the range that is sufficient to affect dissolution. The average carbonate content of core 4 is about twice that of core 5, despite the fact that core 4 is in deeper water. We suspect that the high carbonate content of core 4 relative to core 5 can be attributed to downward advecting water at core 5 and upward advecting water at core 4 .

Upward water advection should not only affect the preservation of carbonate at the sediment-water interface but should also have effects at the sediment-basement interface. Hydrothermal water from the Galapagos has a low $\mathrm{pH}$ and a high $\mathrm{CO}_{2}$ content, both of which should cause undersaturation with respect to carbonate. A location with upwelling water will undergo dissolution of carbonate at the sediment-basement interface. Unless upwelling is extremely rapid, the upward moving water will eventually become saturated with carbonate. This upward moving saturated water will impede carbonate dissolution at the sediment-water interface. For all but the fastest upwelling, the section will have a carbonate-free basal layer accompanted by a carbonate-rich surface layer. Sediments with this pattern of carbonate distribution have been observed near the East Pacific Rise at depths close to the carbonate compensation depth (CCD) [Sundquist et al., 1977]. The high carbonate layers are not repeated downcore, so that this effect is not solely climatic. The thickness of the high carbonate layers is 30 to $65 \mathrm{~cm}$, too great for later bioturbation to $\mathrm{mix}$ this layer Into the zone of dissolution.

\section{Conclusions}

We have presented evidence from thermal gradients, pore water compositions, consolidation tests, and relative carbonate contents that water is moving through areas of sediment cover less

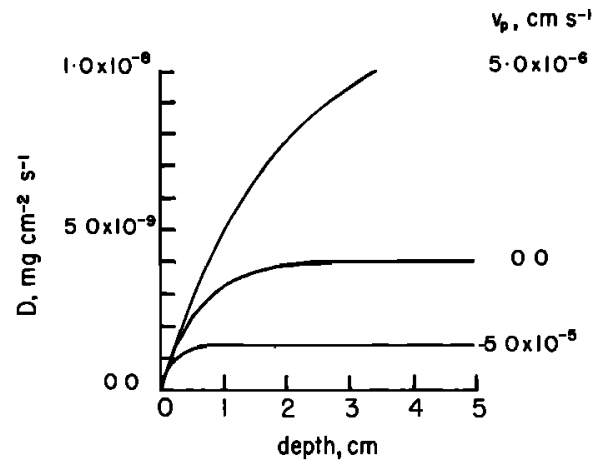

Fig. 13b. Cumulative dissolution D of carbonate ion as a function of depth in the sediment column for several different advection velocities $v_{p}$. Note that upward advecting water results in only a small amount of dissolution that is concentrated in a boundary layer near the sediment-water interface. Downward advecting water results in a much larger amount of dissolution which is spread over a larger depth range. See Table 6 for list of parameters used in calculations.

than $100 \mathrm{~m}$ thick in the Mariana Trough. The proportion of the seafloor covered by less than $100 \mathrm{~m}$ of sediment is quite substantial, even in older areas of oceanic crust.

The advection rates needed to affect chemical gradients may be much higher than previously assumed for two reasons. As shown in our model of carbonate dissolution, a chemical reaction with a nonlinear $(>1)$ rate constant which is modeled as a linear reaction will consistently underestimate the advection rate needed to cause a given change in the pore water profiles of that cation. If chemical reactions are occurring in the sediment column which produce the same product as a basaltic reaction but are not included in calculations of advection rates, the water advection rate needed to perturb a given chemical profile will also be underestimated.

Thermal and chemical observations indicate that water circulation continues in the basalt for tens of millions of years. If water circulation continues in the basalt, then excess pore pressures at the sediment-basement interface should continue to be high.

\section{Append 1x:}

\section{A Quantitative Model of Carbonate Dissolution}

Our model makes three main assumptions about the processes governing carbonate dissolution.

1. We assume that the rate of mass dissolution $R$ of carbonate ion per cubic centimeter of sediment depends only upon the degree of saturation of the pore water with respect to $\mathrm{CO}_{3} \overline{3}$ and the surface area of carbonate exposed to the pore water. We can then write

$$
R=A(1-n) \mathbf{f}
$$

where $A$ is the surface area of carbonate per unit volume of carbonate, $n$ is the porosity of the sediment, $f$ is the volume fraction of solid particles that are carbonate, and $F$ is the rate of dissolution of carbonate per square centimeter of exposed carbonate. The function $F$ depends upon the de- 
gree of saturation and rapidly increases as the pore water becomes undersaturated with carbonate. Experimental results [Morse, 1978] show that $F$ has the functional form

$$
F=a\left[\frac{\delta}{C_{s}}\right]^{p}
$$

where $C_{s}$ is the saturation concentration of carbonate ion and $\delta=\mathrm{C}_{s}-\left[\mathrm{CaCO}_{3}\right]$ describes the degree of undersaturation of the pore water. The coefficient $a$ and exponent $p$ are determined by fitting (A2) to data. Results of Takahashi and Honjo [1982] suggest that $p$ is between 3 and 4, while those of Morse [1978] suggest that $p$ is about 5 .

2 . We assume that the exposed carbonate surface area $A$ can be calculated from a knowledge of the carbonate grain slze distribution of the sediment and that $A$ is constant with both depth in the sediment column and time. By this assumption we ignore the effect the dissolution of the carbonate has on changing the grain size distribution of the sediment. This assumption is necessary both as a mathematical simplification and because of the lack of relevant experimental data. We note that if the sediment contains spherical carbonate grains of mean size $\phi_{O}$ and standard deviation $\sigma$, then

$$
A=\frac{3}{r_{0}} \exp \left[\frac{1}{2}\left(\begin{array}{lll}
\sigma & \ln 2)^{2}
\end{array}\right]\right.
$$

where $r_{o}$ is the radius of a particle of size $\phi_{0}$.

3. We assume that the only two processes that move carbonate through the sediment are diffusion and advection and that these two processes act to move carbonate in only the vertical direction. The nonlinear differential equation that describes the dissolution of carbonate is then

$$
\frac{d^{2} \delta}{d x^{2}}=\frac{v}{K} \frac{d \delta}{d x}+\frac{A(1-n) f a}{K}\left(\frac{\delta}{C_{s}}\right)^{p}
$$

where $x$ is the depth subbottom, $K$ is the diffusion coefficient, and $v$ is the volume flux of the pore water (positive downward). Note that $v$ equals the pore water velocity $v_{p}$ multiplied by the porosity n. We shall sometimes use the abbreviation

$\mathrm{E}=\mathrm{A}(1-\mathrm{r}) \mathrm{f} \mathrm{aC}_{\mathrm{s}}-\mathrm{P}$.

We study carbonate dissoution by solving (A4) with the boundary conditions that the surface degree of undersaturation $\delta_{0}$ is equal to that of the bottom water and that the pore water is completely saturated at great depth within the sediment.

Equation (A4) appears to have no analytic solution. However, it can be easily solved by Runga-Kutta numerical integration. We have found that a useful quantity that can be calculated from the solution is the cumulative amount of carbonate ion dissolved out of the sediment column per unit time from the sediment-water interface down to some depth $x$. The cumulative dissolution of carbonate ion is given by

$$
D(x)=\int_{0}^{x} R(x) d x
$$

Since the dissolution rapidly decreases with depth, the total cumulative dissolution $D_{\infty}=D(x+\infty)$ is a constant.
We can use these quantities to estimate the change in carbonate content of the sediment with depth if we assume that the surface sedimentation rate $V_{S}$ is constant over time and that the exposed surface area of carbonate per unit volume of sediment does not change greatly even though some of the carbonate is lost through dissolution. Then the carbonate volume $1(x)$ lost from a given volume of sediment with a given depth burial is proportional to the dissolution rate $R(x)$ and the time spent at that depth. This time is proportional to the sedimentation rate at that depth

$v(x)=v_{s} u(x) / u_{s}$. Here $u(x) / u_{s}$ gives the ratio of sediment volumes between the surface and depth $x$. The loss of volume is assumed to be entirely due to carbonate dissolution. The loss is then $1(x)=m R(x) u(x) p_{c}-1 v-1(x) d x$, where $P_{c}$ is the density of the carbonate grains, and In 19 the ratio of gram atomic weights of calcium carbonate to calcium lon. The total loss down to depth $x$ is then the integral of $1(x)$, which can then be related to the volume fraction $f(x)$ of solid materlal that is carbonate.

$$
f(x)=\frac{f_{0}-\left\{[m D(x)] /\left[p_{c} V_{s}\left(1-n_{0}\right)\right]\right\}}{1-\left\{[m D(x)] /\left[p_{c} V_{s}\left(1-n_{0}\right)\right]\right\}}
$$

where $f$ and $n$ are the carbonate fraction and porosity at the sediment-water interface and is the density of the carbonate grains. Since the cumulative dissolution increases with depth, this formula predicts a decrease of carbonate fraction with depth. However, if $m D(x)>f_{o} p_{c} V_{s}\left(1-\eta_{b}\right)$, the equation ylelds an unphysical negative result. This error results from our assumption that the dissolution of carbonate is unaffected by the amount of carbonate left in the sediment. Since $\mathrm{mD}(\mathrm{x})$ represents the amount of carbonate lost from the sediment per unit time and $f \quad V(1-n)$ represents the amount added per unit time, the inequality implies that (A6) can be used only when more carbonate is sedimented than is dissolved. The age $T$ of the sediment is then given by

$$
T(x)=v_{s}^{-1} \int_{0}^{x} \frac{d x}{1-\left[m D(x) / p_{c} v_{s}\right]}
$$

and its porosity by

$$
\mathrm{n}(\mathrm{x})=\frac{\mathrm{n}_{\mathrm{o}}}{1-\left[\mathrm{mD}(\mathrm{x}) / \mathrm{P}_{\mathrm{c}} \mathrm{V}_{\mathrm{s}}\right]}
$$

Note that since the process of compaction has been excluded from the model, the porosity actually increases somewhat with depth.

In the spectal case of $p=1$, (A4) has a simple analytic solution, which serves to illustrate the way in which diffusion and advection interact. We find that

$$
\delta(x)=\delta_{0} \exp (-g x) ;=\frac{\left[v^{2}+4 K E\right]^{1 / 2}-v}{2 K}
$$

$$
D(x)=\frac{E \delta_{0}}{g}[1-\exp (g x)]
$$




$$
D \dot{\infty}=\frac{E \delta_{0}}{g}
$$

The function $\mathrm{g}$ can be shown to decrease monotonically with increasing water flux $v$. Therefore the cumulative dissolution at infinity decreases as $v$ is increased. We can show that for small advection rates the cumulative dissolution is approximately given by

$$
D \infty=\delta_{0}(E K)^{12}+\frac{1}{2} \delta_{0}^{v}
$$

while at very high advection rates it is

$$
\mathrm{D} \infty_{\infty}=\left\{\begin{array}{l}
\delta_{\mathrm{O}} \mathrm{v} ; \mathrm{v} \gg(\mathrm{EK})^{1 / 2} \\
0 ;-\mathrm{v} \gg(\mathrm{EK})^{1 / 2}
\end{array}\right.
$$

Note that the effect of increasing the advection rate is only half as strong for small $v$ than it is at very large positive $v$.

When elther the effect of diffusion or advection can be ignored (A4) has analytic solutions for all values of $p$. When there is no advection, we find that

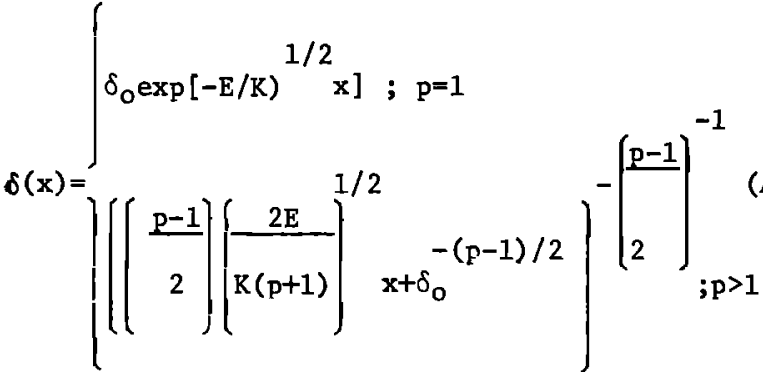

$$
\begin{aligned}
& \mathrm{D}(\mathrm{x})=\int_{(\mathrm{EK})^{1 / 2} \delta_{\mathrm{o}}\left(1-\exp \left[-(\mathrm{E} / \mathrm{K})^{1 / 2} \mathrm{x}\right]\right) ; \mathrm{p}=0} \\
& \int_{D_{\infty}=\delta_{0} \delta_{0 K]^{1 / 2}}(p+1) / 2}\left[\begin{array}{l}
2 E K]^{1 / 2} \\
p+1
\end{array}\right]^{1 / 2}
\end{aligned}
$$

When there is a sufficiently fast downward advection of water, diffusion will everywhere be insignificant compared to advection. We then find that

$$
\begin{aligned}
& \int \delta_{\mathrm{o}} \exp [-\mathrm{Ex} / \mathrm{v}] ; \mathrm{p}=1 \\
& \delta(x)= \\
& {\left[\delta_{0}^{1-p}+(p-1)^{\frac{E x}{v}}\right)^{1 /(1-p)} ; p>1} \\
& \int \delta_{0}(1-\exp [-\mathrm{Ex} / \mathrm{v}]) ; \quad \mathrm{p}=1 \\
& D(x)= \\
& v\left(\delta_{0}-\left[\delta_{0}^{\left.1-p+p^{2}+1\right)} x\right)^{1 /(1-p)}\right] ; p>1 \\
& D_{\infty}=v \delta_{0} \quad ; p \geqq 1
\end{aligned}
$$

When there is an upward advection of water, nelther advection nor diffusion can be ignored. Everywhere except near the sediment-water interface the pore water is nearly saturated, and advection dominates. However, near the sediment-water interface the degree of saturation rapidly changes from close to saturation to close to the state of the ocean bottom water. In this region the concentration gradients are very high, and diffusion plays an important role. Although we cannot find an analytic solution for this case, we can derive an approximate relationship for the cumulative dissolution bv examining the carbonate transport across the sediment-water interface. There is a net loss of carbonate through diffusion equal to $K \nabla \delta$. Since almost all the change in concentration occurs in a thin boundary layer, the gradient can be approximated by $V \delta^{2} \delta / h$, where $h$ is the thickness of the boundary layer. There is also a net gain of carbonate by advection equal to $\delta_{0} \mathrm{v}$, since the pore water is completely saturated at infinity and has an unsaturation of $\delta$ when it crosses the sedimentwater interface. The cumulative dissolution is therefore

$$
\left.D_{\infty}=\delta_{0} \mid \frac{K}{H}-v\right)
$$

Note that both $D_{\infty}$ and $h$ are unknown quantities. However, when the advection velocity is very large, the cumulative dissolution is effectively zero and $\mathrm{h} \approx \mathrm{K} / \mathrm{v}$.

Acknowledgments. We thank Roger Anderson, Michael Bender, Michael Hobart, and Margaret Leinen for their review of the original manuscript and for the improvements they suggested. This research was supported by the National Science Foundation under contract OCE-78-19076. LamontDoherty contribution 3383 .

\section{References}

Abbott, D. H., W. H. Menke, M. Hobart, and R. N. Anderson, Evidence for excess pore pressures in 
southwest Indian Ocean sediments, J. Geophys. Res. 86, 813-828, 1981 .

Aflin-Pyzik, I.B., and S. E. Sommer, Microscale chemical effects of low temperature alteration of DSDP basaltic glasses, J. Geophys. Res., 86, 9503$9510,1981$.

Anderson, R. N., and M. A. Hobart, The relation between heat flow, sediment thickness, and age in the eastern Pacific, J. Geophys. Res., 81, 2868$2989,1976$.

Anderson, R. N., and M.D. Zoback, Permeability, underpressures and convection in the oceanic crust near the Costa Rica Rift, eastern equatorial Pacific, J. Geophys. Res., 87, 2860-2868, 1982.

Anderson, R. N., M. A. Hobart, and M. G. Langseth, Convective heat transfer in oceanic crust and sediment in the Indian Ocean, Science, 204, 828$832,1979$.

Anderson, R. N., M. A. Hobart, S. Uyeda, Heat flow and hydrothermal convection in the oceanic crust of the Marianas Trough, submitted to J. Geophys. Res., 1982.

Becker, K., and R. P. Von Herzen, Rates of hydrothermal convection at the Galapagos mounds area deduced from temperature measurements (abstract), EOS Trans., AGI, 62, 310, 1981.

Bodvarsson, G., and R. P. Lowell, Ocean floor heat flow and the circulation of interstitial waters, J. Geophys. Res., 77, 4472-4475, 1972.

Brace, W. F., Permeability of crystalline and argillaceous rocks, Int. J. Rock Mech. Scl. Geomech. , 17, 241-251, 1980 .

Bredehoeft, J. D., and I. S. Papadopoulos, Rates of vertical groundwater movement estimated from the earth's thermal profile, Water Res., 1 , 325-328, 1965.

Davis, E. E., and C. R. B. Lister, Fundamentals of ridge crest topography, Earth Planet. Sci. Lett., $21,405-413,1974$.

Elderfield, H., N. Luedtke, R. J. McCaffrey, and M. Bender, Benthic flux studies in Narragansett Bay, Am. J. Sci., 281, 278-287, 1981.

Gartling, D. K., and R. N. Anderson, Finite element model of two-layer porous media convection in the oceanic crust and overlying sediments, submitted to J. Geophys. Res., 1982.

Gieskes, J. M., and J. Johnson, Interstitial water studies leg 60, Initial Rep. Deep Sea Drilling Prof. , 60, 749-754, 1982.

Hartline, B. K., and C. R. B. Lister, Topographic forcing of supercritical convection in a porous medium such as the oceanic crust, Earth Planet. Sci. Lett., 55, 75-86, 1981.

Heath, G. R., T. C. Moore, and J. P., Dauphin, Organic carbon in deep-sea sediments, in; The Fate of Fossil Fuel Co in the Oceans, R.N. Anderson and A. Malahoff, Plenum Press, N.Y., pp.605-625, 1977.

Honjo, S., Blogenic carbonate particles in the ocean, do they dissolve in the water column? in; The Fate of Fossil Fuel $\mathrm{CO}$ in the Oceans, edited by R. N. Anderson and A. Malahoff, Plenum Press, N.Y., Pp.269-294, 1977.

Kelly, W. E., R. A. Gularte, and R. M. Heavers, Erosion resistance and shear strength of weak cohesive sediments (abstract) EOS Trans., AGU, $61,998,1980$.

Lambe, W. T., and R. V. Whitman, Soil Mechanics, John Wiley, New York, 1979.

Lawrence, J. R., and J. M. Gieskes, Constraints on water transport and alteration in the oceanic crust from the isotopic composition of pore water, J. Geophys. Res.,86, 7924-7934, 1981.

Lister, C. B. R., On the thermal balance of a midocean ridge, Geophys. J. R. Astron. Soc., 26, 515-535, 1972 .

Lister, C. R. B., The heat flow consequences of the square root law of ridge topography, (abstract), IUGG, Grenoble,1975.

Maris, C. J., M. Bender, P. Froelich, N. Luedtke, K. Becker, J. Corliss, and R. P. Von Herzen, Convection in sediments in the Galapagos hydrothermal mounds field shown from pore water calcium profiles (abstract), EOS Trans., AGU, 60, 737, 1979.

Morse, J. W., Dissolution kinetics of calcium carbonate in sea water: VI. The near equilibrium dissolution kinetics of calcium carbonate-rich deep sea sediments, Am. J. Sc1., 278, 344-353, 1978.

Nickerson, C.R., Consolidation and permeability characteristics of deep sea sediments: north central Pacific ocean, M.S. Thesis, Worcester Polytechnic Institute, 1975.

Parsons, B., and J. G. Sclater, An analysis of the varlation of ocean floor bathymetry and heat flow with age, J. Geophys. Res., 82, 803-827, 1977.

Sayles, F.R., The composition and diagenesis of interstitial solutions, II., Fluxes and diagenesis at the water-sediment interface in the high latitudes of the North Atlantic, Geochim. Cosmochim. Acte, 45, 1061-1086, 1981 .

Schink, D. R., K. A., Fanning, and M. E. Q. Pilson, Dissolved silica in upper pore waters of the Atlantic Ocean floor, J. Geophys. Res., 79, 2243$2250,1974$.

Schink, D. R., N. L. Guinasso, Jr. and K. A. Fanning, Processes affecting the concentration of silica at the sediment-water interface of the Atlantic Ocean, J. Geophys. Res., 80, 3013-3031, 1975.

Sclater, J. G., and K. D. Kl1tgord, A detailed heat flow, topographic and magnetic survey across the Galapagos spreading center at $86^{\circ} \mathrm{W}$, J. Geophys. Res., 78, 6951-6975, 1973.

Sundquist, E., D. K. Richardson, W.S. Broecker, and $T$. H. Peng, Sediment mixing and carbonate dissolution in the southeast Pacific Ocean, in; The Fate of Fossil Fuel Co in the Oceans, edited by R. N. Anderson and A. Malahoff, Plenum Press, N.Y. Pp.429-454, 1977.

Takahashi, T., and S. Honjo, Relationship between the dissolution rates and the chemistry of deep ocean water in the North Atlantic, in prep., 1982.

Takahashi, T., W. S. Broecker, A. E. Bainbridge and R. F. Welss, Carbonate chemistry of the Atlantic, Pacific and Indian oceans: The results of the GEOSECS expeditions 1972-1978, Tech. Rep. 1, Lamont-Doherty Geol. Observ. of Columbia Univ., Palisades, N.Y., 1980.

Theide, J., Textural variations of calcareous coarse fractions in the Panama Basin (eastern equatorial Pacific), in, The Fate of Fossil Fuel $\mathrm{CO}_{2}$ in the Oceans, edited by R.N. Anderson and A. Malahoff, Plenum Press, N.Y. pp.673-692, 1977. Uyeda, S., and K. Hora1, Heat flow measurements on Deep Sea Drill. Proj., 60, Initial Rep. Deep Sea Drill. Proj., 60, 789-802, 1982.

(Received December 1, 1981;

revised August 24, 1982;

accepted September 2, 1982.) 